\title{
Transport Phenomena in Films and Coatings Including Their Mathematical Modeling
}

\author{
M. Alejandra Garcia and Noemí E. Zaritzky
}

\section{CONTENTS}

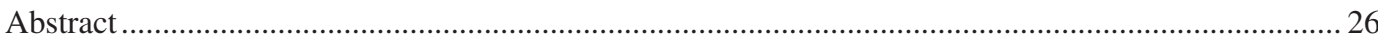

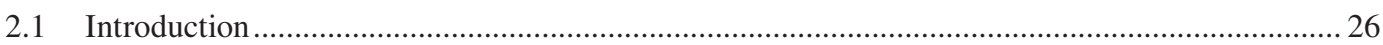

2.2 Edible Coatings to Control Oil Uptake in Fried Foods ………..................................................... 27

2.2.1 Case Study: Heat and Mass Transfer in Frying Processes............................................... 27

2.2.2 Mathematical Model of Heat and Mass Transfer during Frying Process ......................... 28

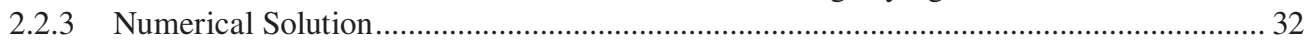

2.2.4 Validation of the Mathematical Model: Frying Process of a Coated Dough Disc ........... 32

2.2.4.1 Description of the Food System and Selection of the Frying Conditions ......... 32

2.2.4.2 Application of a Hydrocolloid Coating to Reduce Oil Uptake during Frying....... 33

2.2.4.3 Heat Transfer Validation: Thermal Histories of Coated and Uncoated

Samples during the Frying Process .................................................................. 33

2.2.4.4 Water Transfer.............................................................................................. 33

2.2.4.5 Temperature and Water Content Predictions Using the

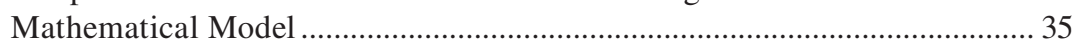

2.2.5 Oil Uptake of Coated and Uncoated Products ............................................................... 35

2.2.6 Quality Attributes of Coated and Uncoated Fried Samples............................................... 37

2.2.7 Microstructure Analysis of the Fried Product................................................................... 39

2.2.8 Relationship between Oil Uptake and Microstructure Changes during
the Frying Process ....................................................................................................... 40

2.2.9 Final Considerations about the Modeling of Coated Fried Food....................................... 42

2.3 Case Study: Release of an Antimicrobial Agent from a Biodegradable

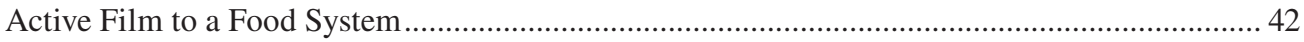

2.3.1 Active Film Preparation and Characterization................................................................. 43

2.3.2 Effect of PS on Optical and Barrier Properties of the Active Films................................. 43

2.3.3 Experiments to Determine PS Release from the Active Film

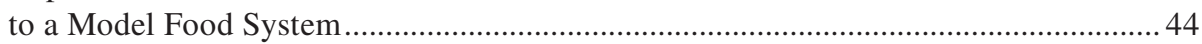

2.3.4 Mathematical Modeling of PS Diffusion Process................................................................ 44

2.3.5 Diffusion Coefficients Determination........................................................................... 45

2.3.6 Application of Active Films in Dairy Products: PS Minimum
Inhibitory Concentration......................................................................................... 47

2.3.7 Antimicrobial Performance of the Active Film on a Dairy Product................................. 47

2.3.8 Final Considerations about the Modeling of the Preservative

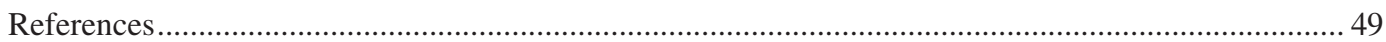




\section{Abstract}

In the present chapter, two examples related to transport phenomena in films and coatings are discussed.

One of them represents the heat and mass transfer process in fried foods that were covered with an edible coating based on methylcellulose (MC). This is an alternative to reduce oil uptake (OU) in fried foods due to its lipid-barrier properties. The following aspects are discussed: (1) mathematical modeling of heat and moisture transfer during the deep-fat frying of food, (2) experimental validation of the mathematical model with regard to the temperature profiles and the water losses from the food product, (3) analysis of the relationship between the OU measurements and microstructural changes developed, and (4) performance of applying an edible coating based on MC on a food model dough system.

The mathematical model of the frying process based on the numerical solution of the heat and mass transfer differential equations under unsteady-state conditions was proposed and solved. It allows simulating satisfactorily the experimental data of temperature and water content during the different frying stages. OU was also linearly correlated with water loss at the initial frying stage. A simple equation for $\mathrm{OU}$ as a function of frying times was proposed, considering the microstructural changes developed during the frying process. The presence of MC coating reduced the OU, modifying the wetting properties and also becoming a mechanical barrier to the oil.

The second example represents the mathematical modeling of potassium sorbate release from a starch biodegradable active film to a model food system represented by a gel in contact with the active film. Mass transfer partial differential equations in nonstationary conditions were numerically solved using the finite element method. The model assumes a constant initial mass of antimicrobial in the active film that diffuses through the film penetrating in the food system.

The numerical solution allowed the determination of the diffusion coefficients of the antimicrobial agent in both, the film and the gel. Concentration profiles were simulated to predict the time period in which the antimicrobial concentration can be maintained above the critical inhibitory concentration in the packaged food.

Experimental data of sorbate diffusion from active films and from a liquid solution to the semisolid medium were compared with the predicted concentration profiles. The model allows the simulation of nonstationary diffusion of different additives incorporated to polymeric matrixes, taking into account the preservative concentration in the film and the dimensions of the semisolid food system.

\subsection{Introduction}

The food industry is focusing their efforts toward offering to the consumers safer, more nutritious, and high-quality products. The use of edible films and coatings in food protection and preservation has recently increased since they offer several advantages over synthetic materials, such as being biodegradable and environmentally friendly (Tharanathan, 2003). Biopolymer-based materials are well recognized as efficient barriers against $\mathrm{O}_{2}$ and $\mathrm{CO}_{2}$, although they exhibited poor water vapor barrier properties (Lacroix, 2009). Likewise, the ability of edible films to retard moisture, oxygen, aromas, and solute transport may be improved by including additives such as antioxidants, antimicrobials, colorants, and flavors, fortifying nutrients in film formulation (Pranoto et al., 2005).

Besides, polysaccharide-based films have been described as oil barriers. The application of hydrocolloid coatings allows the reduction of oil content in deep-fat fried products due to their lipid-barrier properties. The most widely studied are cellulose derivatives, which exhibit thermogelation (BertoliniSuárez et al., 2008).

In addition, studies dealing with edible films with antimicrobial properties are enhanced in the last

AQ1 years. These films could prolong the shelf life and ensure the safety of foods by preventing the growth of pathogenic and spoilage microorganisms as a result of their lag-phase extension and/or their growth rate reduction (Quintavalla and Vicini, 2002).

Hydrophilic matrices have been used as controlled delivery systems in the last decades, due to their low cost and the simple technology associated. This technology has been widely studied in the 
pharmacological area. Although numerous investigations on drug release from hydrophilic matrices have been developed, the mechanisms that drive the mass transfer process is still a matter of debate. The incorporation of active agents into polymeric systems results in a variety of release profiles with different stages. In some cases, the active compound release has been described as a simple matrix diffusion process, with degradation occurring at a later stage, post-active compound release (Gallagher and Corrigan, 2000).

In the present chapter, two examples related to transport phenomena in films and coatings are discussed.

One of them corresponds to the heat and mass transfer process in fried foods that were covered with an edible coating. The second example represents the mathematical modeling of potassium sorbate (PS) release from a starch biodegradable active film to a model food system represented by a gel in contact with the active film.

\subsection{Edible Coatings to Control Oil Uptake in Fried Foods}

The great volume of production of fried foods and its influence on the consumption of lipids enhanced the study of the frying process because of its strong economic and nutritional impact. From the economical point of view, higher oil contents increase production costs. The reduction of lipid content in fried foods is required mainly owing to its relation with obesity and coronary diseases. An alternative to reduce oil uptake (OU) in fried foods is the use of edible films or coatings.

The application of hydrocolloid coatings allows to reduce oil content of deep-fat fried products due to its lipid-barrier properties; the most widely studied are gellan and cellulose derivatives (Williams and Mittal, 1999a,b; Farid, 2002; Mellema, 2003). Cellulose derivatives, including methylcellulose (MC) and hydroxypropyl methylcellulose exhibit thermogelation, when suspensions are heated, they form a gel that reverts below the gelation temperature, and the original suspension viscosity is recovered (Farid and Chen, 1998). These cellulose derivatives reduce oil absorption through film formation at temperatures above their gelation point, or they reinforce the natural barrier properties of starch and proteins, especially when they are added in dry form (Balasubramaniam et al., 1995).

With regard to the modeling of deep-fat frying of coated foods, Mallikarjunan et al. (1997) and Huse et al. (1998) demonstrated the effectiveness of various edible coatings in reducing oil absorption in starchy products. Williams and Mittal (1999a,b) working on frying of foods coated with gellan gum determined the effectiveness of edible films to reduce fat absorption in cereal products and developed a mathematical model for the process.

\subsubsection{Case Study: Heat and Mass Transfer in Frying Processes}

Frying process is considered one of the oldest cooking methods. It is employed to treat foods thermally and to confer unique textures and tastes; the organoleptic characteristics depend on frying conditions. Frying phenomena occur during the immersion of the product in oil at a temperature of $150^{\circ} \mathrm{C}-200^{\circ} \mathrm{C}$, where a simultaneous heat and mass transfer take place (Singh, 1995; Aguilera and Hernández, 2000).

Heat conduction occurs in the core of the solid food, and it is strongly influenced by the physical properties of the food that are continuously changing during the frying process (Campañone et al., 2010). Simultaneously, convection takes place between the oil and the surface of the food. When the formation of bubbles begins, the heat transfer is accelerated because bubbles contribute to the turbulence of the frying medium; however, the formation of foam in the oil produces a significant decrease in the heat transfer rate (Singh, 1995). Then, the amount of vapor decreases due to the reduction of water content (WC) in the core of the food. The rate of heat transfer toward the food core is influenced by the thermal properties and viscosity of the frying medium and the agitation conditions. During the production of bubbles on the surface, forced convection is the controlling regimen, and the determination of heat transfer coefficients becomes difficult, mainly if bubbles remain attached to the surface.

Water transfer is produced by surface boiling and when evaporation decreases; diffusion of water from the food core toward the surface is the dominant physical phenomenon. Water leaves the product as 
bubbles of vapor and internally migrates by means of different mechanisms (Singh, 1995; Aguilera, 1997; Aguilera and Hernández, 2000). After an initial time, when surface moisture is evaporated, a dehydrated zone begins to form on the surface of the food. Under these conditions, surface temperature is closer to that of the frying medium, while moisture is strongly reduced reaching values close to the bound water value. Thus, an important gradient of moisture between the core and the surface is established.

The mechanism of oil penetration is a subject of controversy (Pinthus and Saguy, 1994; Kassama, 2003; Mellema, 2003). Absorption of oil on the surface of the fried product occurs when samples are removed from the frying medium; the oil that remains on the piece surface enters the product (Pinthus and Saguy, 1994; Ufheil and Escher, 1996; Moreira and Barrufet, 1998; Aguilera and Hernández,

AQ3 2000; Yamsaengsung and Moreira, 2002; Bouchon et al., 2003; Mellema, 2003; Bouchon and Pyle, 2005a,b; Campañone et al., 2010). According to these authors, oil does not invade the product itself, and OU during frying is negligible. Conditions at which products are removed from the frying oil seem decisive for the uptake of oil; this would be related to the adhesion of oil to the surface and draining phenomena.

Several models have been developed for heat, moisture, and fat transfer during frying of foods ( $\mathrm{Ni}$ and Datta, 1999; Yamsaengsung and Moreira, 2002a,b). Ateba and Mittal (1994) developed a model for heat, moisture, and fat transfer in deep-fat frying of beef meatballs. Rice and Gamble (1989) used a simplification of Fick's equation to predict moisture loss and the oil absorption during potato frying. Farkas et al. (1996a,b) developed a model for frying considering heat and moisture transfer, and Singh (2000) treated the crust as a moving boundary.

In the present chapter, the following aspects with reference to the use of edible films to control OU are discussed: (1) the mathematical modeling of the heat and moisture transfer during the deep-fat frying process of food systems as a function of operating conditions, (2) the relationship between OU measurements after the frying process with the effect of frying time on sample microstructural changes and the growth of the dehydrated zone, and (3) the performance of applying an edible coating based on MC on a fried-food model dough system by analyzing moisture content, OU, surface microstructure, and quality attributes (texture and color).

\section{AQ4 2.2.2 Mathematical Model of Heat and Mass Transfer during Frying Process}

A mathematical model of the frying process was proposed based on the numerical solution of heat and mass transfer partial differential equations under unsteady-state conditions. The frying process was modeled for food discs (Bertolini-Suárez et al., 2008; Campañone et al., 2010). Discs were considered as infinite slabs and unidirectional; heat and mass transfer equations were solved for $0 \leq x \leq L$ ( $L=$ half the thickness of the sample). In the proposed model, different stages were considered.

Stage 1: Coupled equations represent the initial heating of the product in which energy and mass transfer between the product and the frying oil occurs. The model considered an initial uniform temperature distribution in the sample $\left(T_{i n i}\right)$.

To get the temperature profiles, the following microscopic energy balance was solved:

$$
\rho c_{p} \frac{\partial T}{\partial t}=\nabla(k \nabla T)
$$

Thermal properties corresponded initially to the nonfried product and changed with temperature and moisture content.

The initial and boundary conditions were

$$
\begin{gathered}
t=0 \quad T=T_{\text {ini }} \quad 0 \leq x \leq L \\
x=0 \quad \frac{\partial T}{\partial x}=0 \quad t>0
\end{gathered}
$$




$$
x=L \quad-k \frac{\partial T}{\partial x}=h_{1}\left(T-T_{\text {oil }}\right)+L_{\text {vap }} m_{\text {vap }, 1} \quad t>0
$$

where

$m_{\text {vap, } 1}$ is the water flux from the product

$h_{1}$ is the convective heat transfer coefficient

The heat transfer mechanism was considered governed by natural convection. The value of the heat transfer coefficient $(h)$ for natural convection was calculated for horizontal plates using two different equations:

$$
\mathrm{Nu}=\frac{0.108 \mathrm{Gr}^{4 / 11} \operatorname{Pr}^{9 / 33}}{\left(1+0.44 \operatorname{Pr}^{2 / 3}\right)^{4 / 11}},(\text { Mallikarjunan et al., 1997) }
$$

$$
\mathrm{Nu}=0.55(\mathrm{Gr} \cdot \mathrm{Pr})^{1 / 4}, \text { (Huse at al., 1998) }
$$

where

$\mathrm{Nu}$ is the Nusselt number

$\mathrm{Gr}$ is the Grashof number

Pr is the Prandtl number

$$
\mathrm{Gr}=\frac{L^{3} \rho_{\text {oil }}^{2} g \beta \Delta T}{\mu^{2}} ; \quad \operatorname{Pr}=\frac{C p \mu}{k}
$$

Table 2.1 shows the physical properties of raw and fried dough system fed to the mathematical model and the properties of the used oil.

The obtained average value of the natural convection heat transfer coefficient for horizontal plates was $h_{1}=50 \mathrm{~W} / \mathrm{m}^{2} \mathrm{~K}$.

\begin{tabular}{|c|c|c|c|}
\hline Property & Core Zone & Dehydrated Zone & Sunflower Oil \\
\hline Initial water content & 0.42 & - & - \\
\hline Density $\left(\mathrm{kg} / \mathrm{m}^{3}\right)$ & $623^{\mathrm{b}}$ & $579^{a}$ & $876^{\mathrm{c}}$ \\
\hline Thermal conductivity (W/[m K]) & $0.6^{\mathrm{b}}$ & $0.05^{\mathrm{a}}$ & $0.6^{\mathrm{c}}$ \\
\hline Specific heat $\left(\mathrm{J} / \mathrm{kg}{ }^{\circ} \mathrm{C}\right)$ & $2800^{\mathrm{b}}$ & $2310^{\mathrm{a}}$ & $2033^{c}$ \\
\hline Viscosity $(\mathrm{Pa} \cdot \mathrm{s})$ & & & $2.04 \times 10^{-3 c}$ \\
\hline Porosity & - & $0.42^{\mathrm{b}}$ & - \\
\hline Tortuosity & - & $8.8^{\mathrm{b}}$ & - \\
\hline $\begin{array}{l}\text { Diffusion coefficient of vapor in air } \\
\text { (dehydrated zone) }\left(\mathrm{m}^{2} / \mathrm{s}\right)\end{array}$ & \multicolumn{3}{|c|}{$\frac{5.68 \times 10^{-9}(T+273.16)^{1.5}}{.789-2.13 \times 10^{-3}(T+273.1}$} \\
\hline $\begin{array}{l}\text { Moisture diffusion coefficient in } \\
\text { dough (core zone) }\left(\mathrm{m}^{2} / \mathrm{s}\right)\end{array}$ & \multicolumn{3}{|c|}{$2 \times 10^{-9 b}$} \\
\hline
\end{tabular}

\section{TABLE 2.1}

Physical Properties of Sunflower Oil and the Dough System (Core and Dehydrated Zones) Used in the Model

a Rayner et al. (2000).

b Campañone et al. (2010).

c Moyano and Pedreschi (2006). 
In order to evaluate water profiles, the microscopic mass balance was solved:

$$
\frac{\partial C_{w}}{\partial t}=\nabla\left(D_{w} \nabla C_{w}\right)
$$

The following are the initial and boundary conditions:

$$
\begin{gathered}
t=0 \quad C_{w}=C_{w, i n i} \quad 0 \leq x \leq L \\
x=0 \quad \frac{\partial C_{w}}{\partial x}=0 \quad t>0 \\
x=L \quad-D_{w} \frac{\partial C_{w}}{\partial x}=m_{\text {vap }, 1} \quad t>0
\end{gathered}
$$

$m_{v a p, 1}$ is calculated from Equation 2.10 with $C_{w}=0$ at the sample/oil interface, because it was considered that water evaporates and immediately leaves the frying medium.

For each time interval, the model calculated the average value of moisture content as follows:

$$
C_{w, a v e}=\frac{\int_{0}^{L} C_{w} d V}{V}
$$

The second stage starts when the surface temperature of the product reaches that of the water vaporization.

Stage 2: Water boiling is produced on the surface, and a dehydrated layer is formed in the external zone of the product, having different thermophysical and transport properties from those of the wet core (Table 2.1). Several authors (Farkas et al., 1996a,b; Ni and Datta, 1999; Bouchon et al., 2003; Bouchon and Pyle, 2005b) used the denomination of crust for the dehydrated zone. In the present work, we considered that the crust is only the portion of the dehydrated zone containing oil.

When water on the surface is no longer available, vaporization occurs inside the product forming a front that moves toward the inner zone. During this phase of the frying process, the vapor being released from the product surface impedes oil penetration into the food (Singh, 1995; Aguilera and Hernández, 2000; Kassama, 2003). Microscopic-energy balances given by Equation 2.1 were solved for both (core and dehydrated) zones to obtain temperature profiles, considering the corresponding thermal properties.

The initial temperature profile in this stage was given by the final profile obtained at the end of Stage 1. The following boundary conditions were applied:

$$
\begin{gathered}
x=0 \quad \frac{\partial T}{\partial x}=0 \quad t>0 \\
x=x_{1} \quad T=T_{\text {vap }} \quad t>0 \\
x=L \quad-k_{d} \frac{\partial T}{\partial x}=h_{2}\left(T-T_{\text {oil }}\right) \quad t>0
\end{gathered}
$$

where $x_{1}$ is the variable position of the vaporization moving front (measured from the center of the slab). Thus, the thickness of the dehydrated zone $\left(d_{Z}\right)$ measured from the sample/oil interface can be calculated as $d_{Z}=L-x_{1}$ (Figure 2.1). 


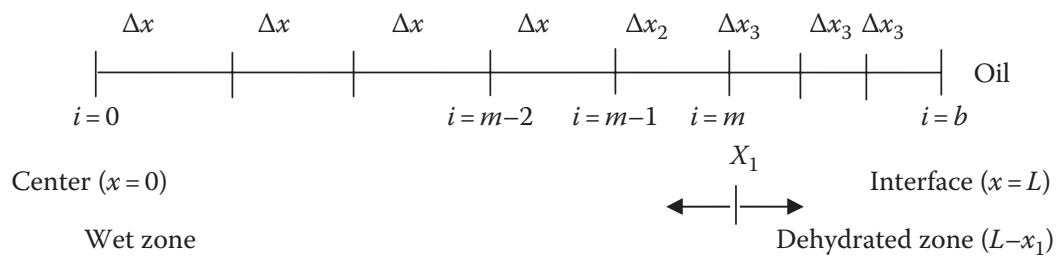

FIGURE 2.1 Scheme of the variable grid employed in the numerical solution (Stage 2).

Values of the heat transfer coefficient $\left(h_{2}\right)$ higher than $250 \mathrm{~W} / \mathrm{m}^{2} \mathrm{~K}$ were found in literature for the whole frying process. Costa and coworkers (1998) reported a value of $h_{2}=650 \pm 7 \mathrm{~W} / \mathrm{m}^{2} \mathrm{~K}$ for potato chips fried at $180^{\circ} \mathrm{C}$; Dagerskog and Sorenfor (1978) reported values of $h_{2}$ ranging between $300-700 \mathrm{~W} / \mathrm{m}^{2} \mathrm{~K}$ for meat hamburgers fried at $190^{\circ} \mathrm{C}$; Moreira et al. (1995) obtained values of 285 and $273 \mathrm{~W} / \mathrm{m}^{2} \mathrm{~K}$ for fresh and used soy oil, respectively. These high-heat transfer coefficients allowed us to assume a constant temperature at the product-oil interface. Moisture content decreased due to water vaporization; vapor diffused through the dehydrated zone, which was considered as a porous medium.

The following mass balance was solved in the dehydrated zone:

$$
m_{v a p, 2}=-D_{v} \frac{\partial C_{v}}{\partial x}
$$

$D_{v}$ was calculated through the following relationship:

$$
D_{v}=D_{v a} \frac{\varepsilon}{\tau}
$$

where

$\varepsilon$ is the porosity of the product

$\tau$ is the tortuosity

The following relationships were considered:

$$
\begin{gathered}
x=x_{1} \quad C_{v}=C_{v, e q u i} \\
x=L \quad C_{v}=0
\end{gathered}
$$

where $C_{v \text {, equi }}$ is the equilibrium vapor concentration at $T_{v a p}$; it was calculated using the ClausiusClapeyron equation, assuming ideal gas behavior for the water vapor.

Water vapor concentration at the product-oil interface was assumed negligible according to Equation 2.18. To calculate the position of the vaporization front $\left(x_{1}\right)$ as a function of time, the following equation was proposed:

$$
-C_{w, a v e} \frac{d x_{1}}{d t}=-D_{v} \frac{\partial C_{v}}{\partial x}
$$

where $C_{w, \text { ave }}$ is the average value of WC in the core calculated at the end of Stage 1, because it represents the volumetric water distribution inside the food. 
Equation 2.19 considers that the amount of water available for vaporization in the core is the same as the humidity travelling in the dehydrated zone; then,

$$
\frac{d x_{1}}{d t}=\frac{D_{v}}{C_{w, \text { ave }}} \frac{\partial C_{v}}{\partial x}
$$

When the vaporization front reaches the center of the fried product, the dehydrated food system increases its temperature until the process is completed. Water transfer is absent, and the moisture content corresponds to the bound water. To estimate temperature profiles, the microscopic energy balance (Equation 2.1) with the boundary conditions (2.3) and (2.14) was solved.

Stage 3: The final step corresponds to the cooling of the fried product when it is removed from the hot-oil medium. The energy microscopic balance (Equation 2.1) was solved with the boundary condition given by Equation 2.3, and considering a natural convection heat transfer coefficient at the food-air interface, as follows:

$$
x=L \quad-k_{d} \frac{\partial T}{\partial x}=h_{3}\left(T-T_{a}\right) \quad t>0
$$

$h_{3}$ can be calculated using the following equation:

$$
h=1.32\left(\frac{\Delta T}{H}\right)^{0.25} \text { for plates with } H=\operatorname{diameter}[35]
$$

with $\Delta T$ as the positive temperature difference between the surface of the fried food and the surrounding air. In this step, the OU is produced.

The mathematical model was solved for the different stages. The microscopic energy and water vapor mass balances led to a system of coupled nonlinear partial differential equations.

\subsubsection{Numerical Solution}

The mathematical model was solved for the different frying stages. Details of the numerical solution based on the finite differences method were reported in Bertolini-Suárez et al. (2008).

The domain has been discretized (Figure 2.1), where 0 indicates the food center, $\mathrm{m}$ the moving front (the point $\mathrm{m}$ moves with time), and $\mathrm{b}$ the surface. The set of equations allowed to calculate temperature profiles as a function of frying times. The number of nodes in each zone changed as long as the vaporization front progressed. At each time step, the position of the moving front was calculated.

\subsubsection{Validation of the Mathematical Model: Frying Process of a Coated Dough Disc}

\subsubsection{Description of the Food System and Selection of the Frying Conditions}

The food system was a wheat flour dough; discs $60 \mathrm{~mm}$ in diameter and $7 \mathrm{~mm}$ thick were cut and immediately utilized. For each experiment, 6 discs were fried. The mathematical model was also validated on dough disc that are $5 \mathrm{~mm}$ thick (Bertolini-Suárez et al., 2008).

Samples were fried in a controlled temperature deep-fat fryer containing commercial sunflower oil. Different constant frying temperatures were tested to select the working frying conditions according to sample characteristics; these temperatures ranged between $150^{\circ} \mathrm{C}$ and $170^{\circ} \mathrm{C}$. Frying times between 5 and $15 \mathrm{~min}$ were analyzed, and an initial temperature of $20^{\circ} \mathrm{C}$ was considered. Optimum time-temperature frying conditions were determined by a nontrained sensory panel of 6 members; panelists judged color, flavor, texture, and overall appearance of the samples as described in a previous work (García et al., 2002).

Frying conditions determine sensory characteristics and consumer acceptability of fried products. Sensory characterization was performed to select time-temperature conditions. Sensory analysis (color, flavor, texture, and overall appearance) determined that $12 \mathrm{~min}$ at $160 \pm 0.5^{\circ} \mathrm{C}$ were the best frying 
conditions for dough discs. Besides, this was the time required to complete starch gelatinization in dough discs (confirmed by microscopy observation), and consequently, fried samples could be considered cooked. Accordingly, this temperature was selected for further determinations and the selecting frying times ranged between 3 and $15 \mathrm{~min}$.

\subsubsection{Application of a Hydrocolloid Coating to Reduce Oil Uptake during Frying}

In order to analyze the effect of the hydrocolloid coating to reduce OU in fried products, coating formulations were prepared using 1\% (w/w) MC (A4M, Methocel) aqueous solution and $0.75 \%(w / w)$ sorbitol (Merck, USA) as a plasticizer. Dough samples were dipped in the coating suspensions for $30 \mathrm{~s}$ and immediately fried at the selected conditions, as previously described (Bertolini-Suárez et al., 2008).

\subsubsection{Heat Transfer Validation: Thermal Histories of Coated and Uncoated Samples during the Frying Process}

Sample temperatures of coated and uncoated samples as a function of frying time were measured using copper-constantan thermocouples (Omega). Temperature measurements in the center of the dough were performed by introducing the thermocouple carefully through the disc from the border toward the center; besides, the temperatures of an internal sample point and the temperature of the frying medium were also recorded.

Temperatures were measured and recorded each $5 \mathrm{~s}$ using type $T$ thermocouples linked to a data acquisition and control system.

Figure 2.2 shows the measured values (symbols) at the center and in an inner point (1.6 $\mathrm{mm}$ from the center). After $120 \mathrm{~s}$ a constant temperature of $100.5^{\circ} \mathrm{C}$ was reached at the core. The core temperature remained constant due to water evaporation, while the temperature in the dehydrated zone increased up to the end of the process $(15 \mathrm{~min})$. Similar results on thermal histories were reported by Costa et al. (1998), working on sliced potatoes fried in sunflower oil at $140^{\circ} \mathrm{C}-180^{\circ} \mathrm{C}$.

A cooling period could be observed when the product was removed from the fryer. In the same figure, simulated temperatures using the proposed model of samples 5 or $7 \mathrm{~mm}$ thick are shown (lines), and a good agreement with the experimental thermal histories is observed.

Experimental thermal histories of coated and uncoated samples did not differ significantly $(p>0.05)$. These results can be explained taking into account that the average coating thickness determined by scanning electron microscopy (SEM) was approximately $10 \mu \mathrm{m}$ (García et al., 2002, 2004) leading to a negligible heat transfer resistance.

\subsubsection{Water Transfer}

WC was determined measuring weight loss of fried products, upon drying in an oven at $110^{\circ} \mathrm{C}$ until constant weight (García et al., 2002). At different frying times, the relative variation of water retention $\%$ (WR) in the coated product relative to the uncoated one was calculated as follows:

$$
W R=\left(\frac{W C \text { coated }}{W C \text { uncoated }}-1\right) \times 100
$$

where $W C$ is the water content of the samples (dry basis). For each frying time condition, results were obtained using all the samples from at least two different batches. The equilibrium WC was defined as the humidity reached at long frying times (1080 s).

Experimental values of WC for coated and uncoated samples are shown in Table 2.2; nonsignificant differences $(p>0.05)$ were detected between coated and uncoated discs. This could be attributed to the poor water vapor barrier of MC films (Donhowe and Fennema, 1993; Debeaufort and Voilley, 1997; Krochta and De Mulder-Johnston, 1997). The equilibrium WC values, which correspond to bound water, were 0.157 and $0.1695 \mathrm{~g}$ water/g dry solid for uncoated and coated samples, respectively. 

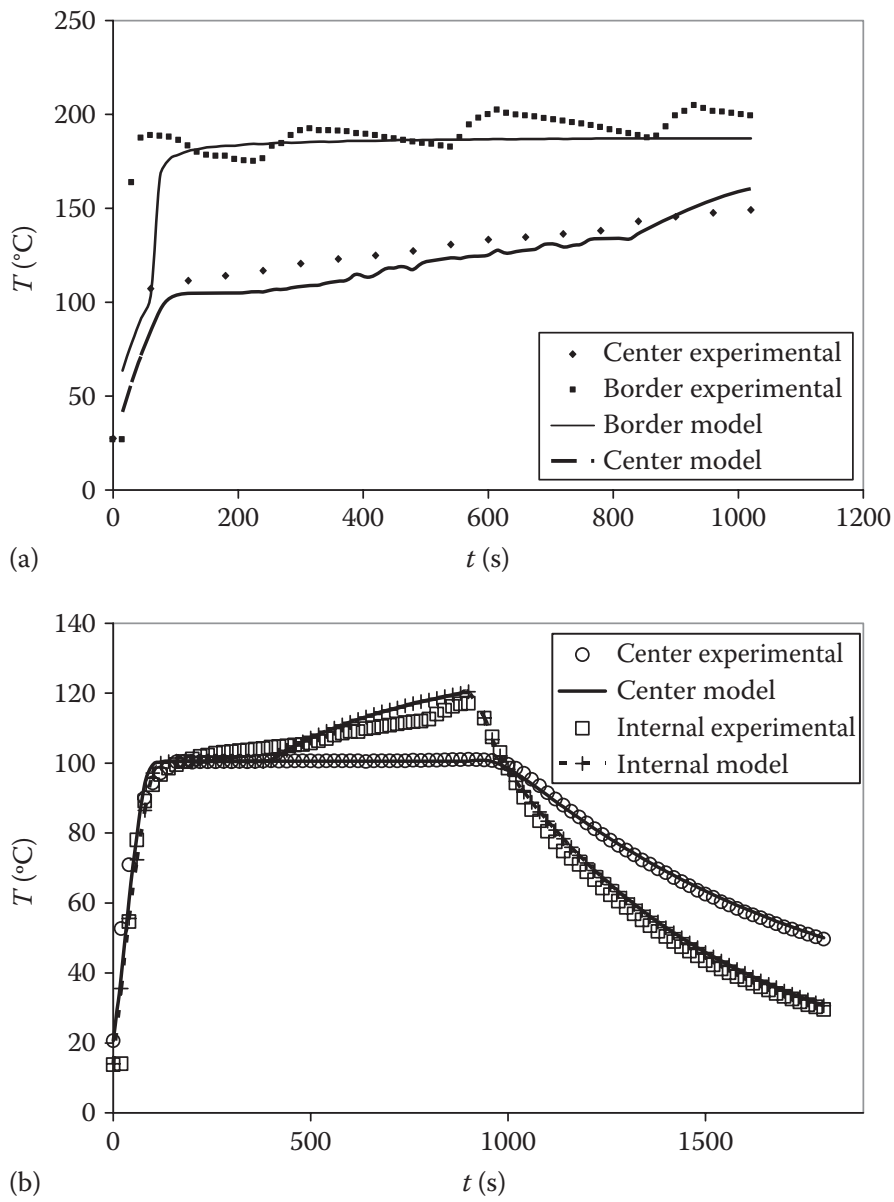

AQ5 FIGURE 2.2 Thermal histories of the fried product at the center and in an internal point (1.6 $\mathrm{mm}$ from the border) along the different frying stages. Experimental data (symbols) and numerical simulations (lines).

TABLE 2.2

Lipid and Water Contents of Uncoated and Coated Dough Discs as a Function of Frying Time

\begin{tabular}{|c|c|c|c|c|c|c|}
\hline Time (s) & $\begin{array}{c}\text { OU of Uncoated } \\
\text { Samples } \\
\text { (g Oil/g Dry Solid) }\end{array}$ & $\begin{array}{l}\text { OU of Coated } \\
\text { Samples } \\
\text { (g Oil/g Dry } \\
\text { Solid) }\end{array}$ & $\begin{array}{l}\text { WC of Uncoated } \\
\text { Samples } \\
\text { (g Water/g Dry } \\
\text { Solid) }\end{array}$ & $\begin{array}{l}\text { WC of Coated } \\
\text { Samples } \\
\text { (g Water/g } \\
\text { Dry Solid) }\end{array}$ & $\begin{array}{l}\text { WR, Water } \\
\text { Retention } \\
\text { Relative } \\
\text { Variation }(\%)\end{array}$ & OUR (\%) \\
\hline 0 & 0.00 & 0.00 & $0.721 \pm 0.043^{\mathrm{a}}$ & $0.786 \pm 0.059$ & 9.09 & - \\
\hline 180 & $0.053 \pm 0.010$ & $0.045 \pm 0.010$ & $0.492 \pm 0.017$ & $0.477 \pm 0.013$ & -3.06 & 14.07 \\
\hline 360 & $0.058 \pm 0.016$ & $0.049 \pm 0.001$ & $0.356 \pm 0.013$ & $0.352 \pm 0.012$ & -1.05 & 15.36 \\
\hline 540 & $0.073 \pm 0.008$ & $0.054 \pm 0.001$ & $0.300 \pm 0.013$ & $0.296 \pm 0.007$ & -1.34 & 26.36 \\
\hline 720 & $0.074 \pm 0.016$ & $0.053 \pm 0.006$ & $0.253 \pm 0.037$ & $0.200 \pm 0.006$ & -21.12 & 29.07 \\
\hline 900 & $0.082 \pm 0.017$ & $0.062 \pm 0.013$ & $0.142 \pm 0.016$ & $0.159 \pm 0.016$ & 11.43 & 24.62 \\
\hline 1080 & $0.089 \pm 0.005$ & $0.063 \pm 0.005$ & $0.157 \pm 0.005$ & $0.170 \pm 0.004$ & 8.03 & 29.91 \\
\hline
\end{tabular}

a Value \pm standard deviation. 


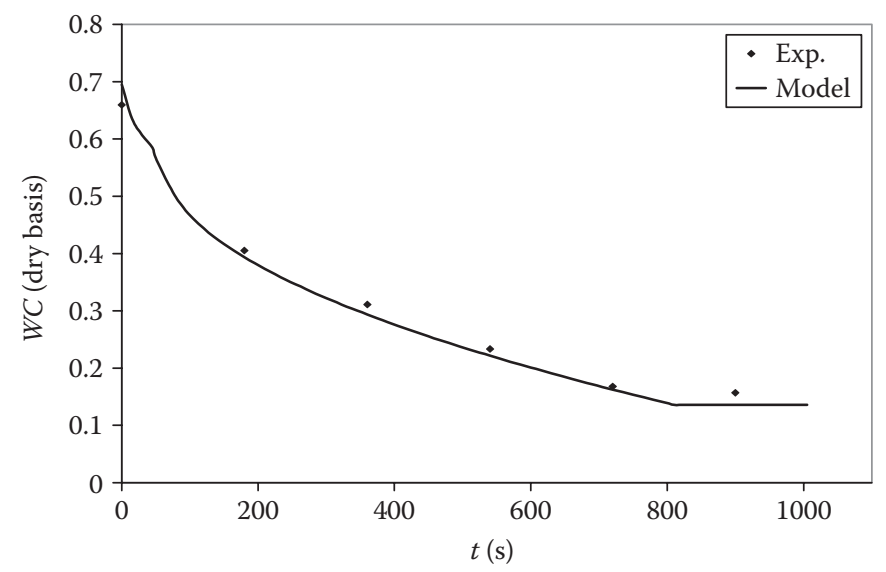

FIGURE 2.3 Water content along the different frying stages. Experimental data (symbols) and numerical simulations (lines).

The presence of the coating did not change the moisture content of the samples during frying because the hydrophilic MC coating became a negligible barrier to water transfer.

Simulated and experimental water concentrations versus frying times are shown in Figure 2.3 for samples that are 5 or $7 \mathrm{~mm}$ thick, and a good agreement was achieved.

Figure 2.4a shows the predicted position of the vaporization front as a function of frying time. At $15 \mathrm{~min}$ of process, the vaporization front reached the center of the product, and the humidity corresponded to the bound water. WC correlated linearly with the vaporization position $x_{1}$ that corresponds to the thickness of the humidity core (Figure 2.4b). Considering $d_{Z}=L-x_{1}$, the following equation was obtained:

$$
W C=0.14893+158.4\left(L-d_{Z}\right) \quad r^{2}=0.9966
$$

\subsubsection{Temperature and Water Content Predictions Using the Mathematical Model}

Once the mathematical model was validated, it was used to predict temperature and WC profiles as shown in Figure 2.5a and $b$ at different frying times.

As can be observed, a sample temperature of the dehydrated zone increased during the frying process reaching values higher than the equilibrium water vaporization temperature.

\subsubsection{Oil Uptake of Coated and Uncoated Products}

OU of fried products was determined measuring the lipid content of dried samples using a combined technique of successive batch and semicontinuous Soxhlet extractions. The first batch extraction was performed with petroleum ether/ethylic ether (1:1) followed by a Soxhlet extraction with the same mixture and another with n-hexane. Oil uptake relative variation \% (OUR) in the coated product relative to the uncoated one was calculated as follows:

$$
O U R=\left(1-\frac{O U \text { coated }}{O U \text { uncoated }}\right) \times 100
$$

For each frying time condition, results were obtained using all the samples from at least two different batches. 

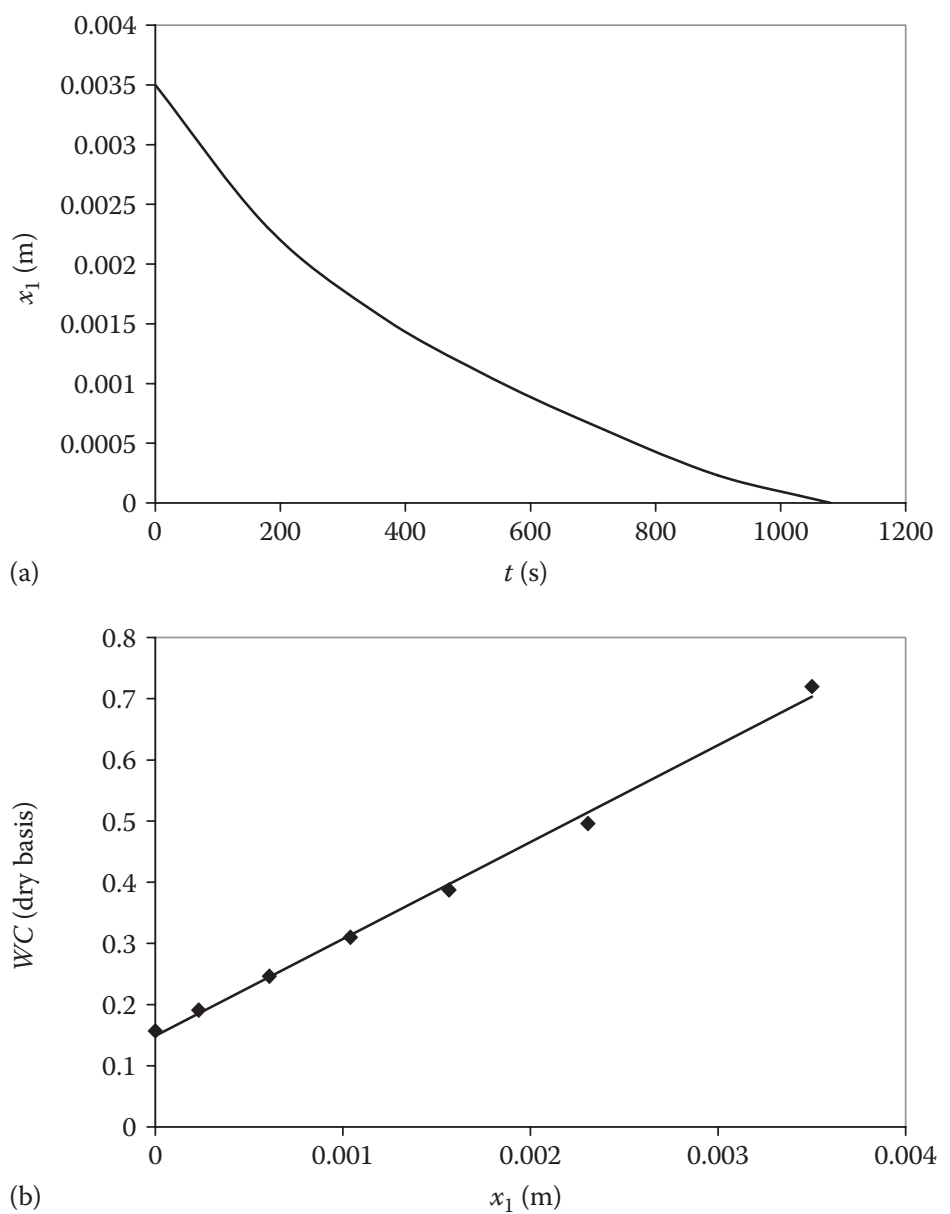

FIGURE 2.4 (a) Position of the vaporization front as a function of frying time and (b) water content of fried dough discs as a function of the position of the vaporization front.

The OU values of coated dough discs at each frying time are shown in Table 2.2. The final lipid content, at long frying times, was $0.0894 \mathrm{~g}$ oil $/ \mathrm{g}$ dry solid for uncoated samples. As can be observed, MC coating reduced the lipid content of dough discs significantly $(P<0.05)$; the OU was $30 \%$ lower than that corresponding to uncoated samples (Table 2.2). Similarly, Williams and Mittal (1999) reported that MC coatings reduced the lipid content of potato spheres by $34.5 \%$ compared to the control samples. This result was attributed to the presence of hydrocolloid films acting as lipid barriers, particularly MC due to its thermal gelation properties. The final lipid content values, at long frying times, for coated samples was $0.0626 \mathrm{~g}$ oil/g dry solid; thus, the ratio between the lipid content $(\mathrm{db})$ of uncoated and coated samples was 1.4 at $1080 \mathrm{~s}$, verifying that the MC coating acted as an effective oil barrier.

Many factors affect OU in deep fat frying, such as oil quality, frying temperature, residence time, product shape and size, product composition (initial moisture and protein content), pore structure (porosity and pore size distribution), and prefrying treatments (drying, blanching, surface coating). Interfacial tension was also reported by Pinthus and Saguy (1994) to have a significant influence on OU after deep-fat frying. The mechanism of oil penetration is a subject of controversy (Kassama, 2003). Many researchers have suggested that fat absorption is primarily a postfrying phenomena (Perkins and Erikson, 1996; Williams and Mittal 1999a; Yamsaengsung and Moereira, 2002; Bouchon et al., 2003); thus, fat transfer occurs in food product during the cooling stage. Moreira and Barrufet (1998) reported that $80 \%$ of the total oil content was absorbed in tortilla chips during the cooling period. 

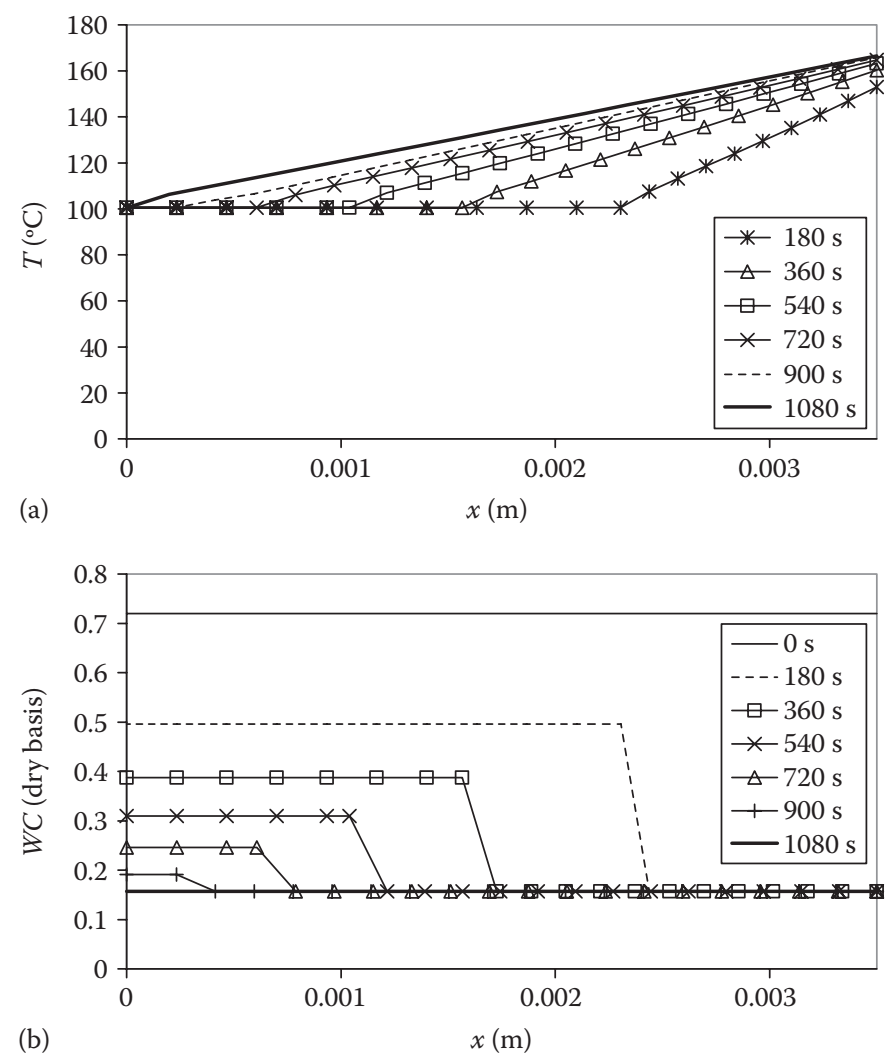

FIGURE 2.5 Profiles of (a) temperature and (b) water content of fried dough disc predicted by the proposed mathematical model.

They explained that as the product temperature decreases the interfacial tension between gas and oil increases, raising capillary pressure. This sucks the surface oil into the porous medium, thus increasing the final oil content.

Ufheil and Escher (1996) also suggested that the absorption theory was based on surface phenomena, which involve the equilibrium between adhesion and the drainage of oil during cooling. Fat absorption in chips due to surface adherence was the result of steam condensation, as was also suggested by Rice and Gamble (1989). OU depends on structural changes during the process; differences in the starting food microstructure can be expected to be important determinants in the evolution of the characteristics of the end product. Meat products are mainly an arrangement of protein fibers, which may relax and denature upon heating (Aguilera and Stanley, 1999), while flour-based products, such as doughnuts and tortilla, have a different microstructure.

\subsubsection{Quality Attributes of Coated and Uncoated Fried Samples}

To evaluate whether MC coating application affected the quality attributes, color and texture parameters, of coated and uncoated fried dough samples were analyzed.

Colorimetric measurements: The CIELab scale was used, lightness $\left(L^{*}\right)$ and chromaticity parameters $a^{*}$ (red-green) and $b^{*}$ (yellow-blue) were measured. $L^{*}, C^{*}$ (chroma), $H^{\circ}$ (hue), and color differences $(\Delta E)$ were also calculated as

$$
\Delta E=\sqrt{\left(\Delta L^{*}\right)^{2}+\left(\Delta a^{*}\right)^{2}+\left(\Delta b^{*}\right)^{2}}
$$


where

$$
\Delta L^{*}=L_{0}^{*}-L_{t}^{*}, \quad \Delta a^{*}=a_{0}^{*}-a_{t}^{*}, \quad \Delta b^{*}=b_{0}^{*}-b_{t}^{*}
$$

being $L_{t}^{*}, a_{t}^{*}$, and $b_{t}^{*}$ as the color parameter values of samples fried at different frying times. $L_{0}^{*}, a_{0}^{*}$, and $b_{0}^{*}$ were selected as the color parameters of samples fried for $3 \mathrm{~min}$ at $160^{\circ} \mathrm{C}$ and not the color of the raw sample in order to analyze the effect of frying time. Samples were analyzed in triplicates, recording four measurements for each sample.

Nonsignificant $(P>0.05)$ differences were observed in the analyzed color parameters of coated and uncoated dough discs. Chromaticity parameter $b^{*}$ increased significantly $(P<0.05)$ with frying time, while lightness $L^{*}$ and chromaticity parameter $a^{*}$ were independent of frying time. Besides, chroma parameter and color differences $(\Delta E)$ increased and hue decreased significantly $(P<0.05)$ as a function of frying time for $t<720 \mathrm{~s}$ (Figure 2.6a). During overcooking of the samples, all parameters remained constant.

Texture analysis: The breaking force of samples was measured by a puncture test using a texture analyzer. Samples were punctured with a cylindrical plunger $(2 \mathrm{~mm}$ diameter $)$ at $0.5 \mathrm{~mm} / \mathrm{s}$. Maximum force at rupture was determined from the force-deformation curves. At least 10 samples
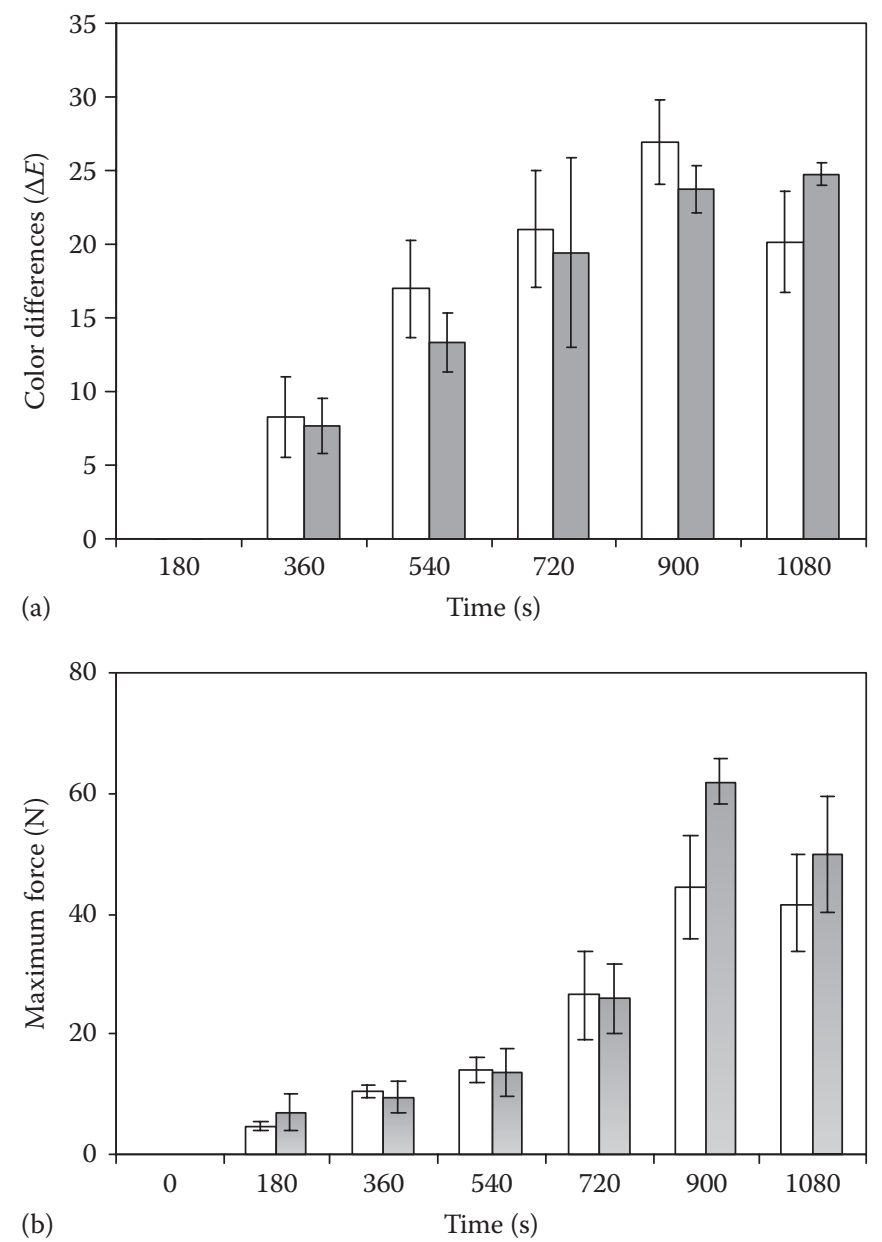

FIGURE 2.6 Quality attributes of coated (filled bars) and uncoated (empty bars) fried dough discs as a function of frying time: (a) color differences and (b) firmness. 
were measured for each assay. Samples were allowed to reach room temperature before performing the tests. During the frying process (for $t<720 \mathrm{~s}$ ), similar values of maximum force were obtained for coated and uncoated fried samples. In all cases, the maximum force to puncture the samples increased as a function of frying time, due the formation of a dehydrated zone (Figure 2.6b). At longer frying times when discs were considered overcooked, the highest maximum forces for coated samples were observed.

With regard to the quality attributes during the cooking process, (for $t<720 \mathrm{~s}$ ) differences between the color parameters and firmness values of coated and uncoated samples were not significant; besides, the panelists could not distinguish between control and coated samples.

\subsubsection{Microstructure Analysis of the Fried Product}

SEM and ESEM techniques were used to observe the structure of the coated and uncoated fried samples (Bertolini-Suárez et al., 2008; Campañone et al., 2010).

The effects of frying time and coating application on the structure were studied. Figure 2.7 shows that MC coating was getting dehydrated during the frying process and remained attached to the surface of the product, explaining the lower lipid content of the coated product. The thickness of the coating was measured on the micrographs obtaining values ranging between 9 and $24 \mu \mathrm{m}$ after $12 \mathrm{~min}$ of frying.

Figure 2.7 also shows the integrity of the MC layer and the good adhesion of this coating to the fried product. The addition of a plasticizer (sorbitol) to MC coatings was necessary to achieve coating integrity (García et al., 2002). Formation of a uniform coating on the surface of the sample is essential to limit mass transfer during frying (Huse et al., 1998). Sorbitol addition improved barrier properties of coatings by decreasing oil content compared to coated samples without a plasticizer. Similarly, Rayner et al. (2000) reported that the performance of a soy protein film applied to dough discs increased by the addition of glycerol as a plasticizer, reducing the fat uptake by the food.

The coating did not prevent the formation of a dehydrated zone on the surface of the dough. The release of water vapor led to the formation of blisters at the outer surface of the crust being smaller in size and number in the coated dough than in the uncoated one. In the first period of frying, the MC coating loses its water, the dough keeps its humidity, and the starch gelatinizes with higher WC than in the uncoated dough, leading to a more compact network (Figure 2.8).

During frying in both coated and uncoated systems, the core was progressively dehydrated, and starch gelatinization was completed at $12 \mathrm{~min}$. The dehydrated zone showed holes due to the water vapor release; the size of the holes increased along the frying process.

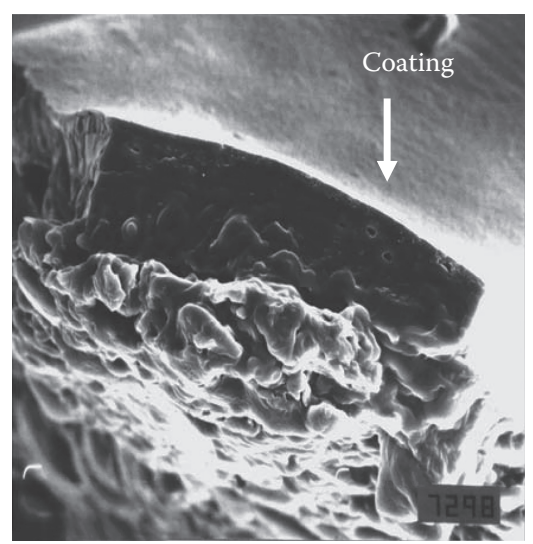

(a)

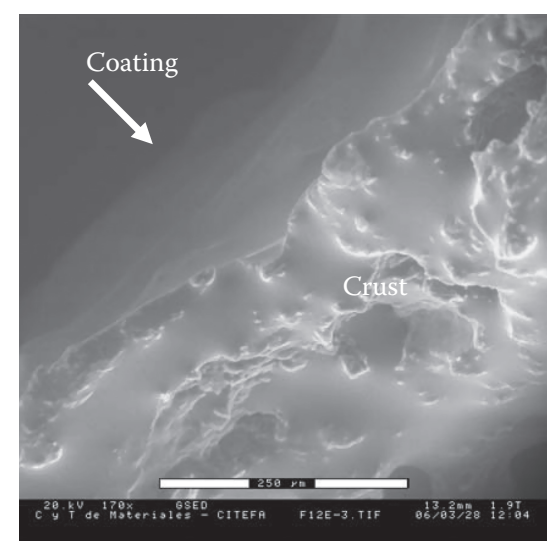

(b)

FIGURE 2.7 Cross-sectional micrographs of a fried dough disc coated with $1 \%$ methylcellulose plasticized with $0.75 \%$ sorbitol: (a) scanning electron microscopy, magnification $100 \mu \mathrm{m}$ between marks, and (b) ESEM. 


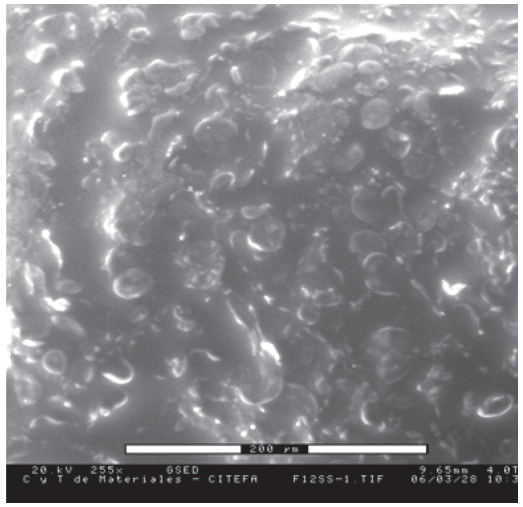

(a)

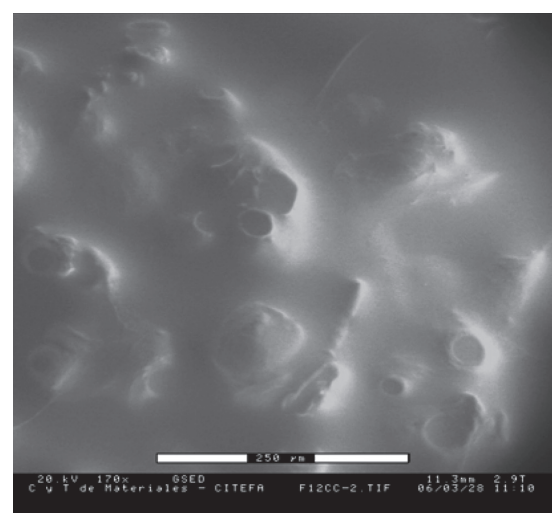

(b)

FIGURE 2.8 ESEM micrographs of a dough disc fried during $12 \mathrm{~min}$ : (a) surface of the uncoated sample and (b) surface of the coated sample.

\subsubsection{Relationship between Oil Uptake and Microstructure Changes during the Frying Process}

OU depends on structural changes during the process; differences in the starting food microstructure can be expected to be important determinants in the evolution of the characteristics of the end product. Microstructural changes were produced during frying time; the dehydrated zone increased allowing the oil retained by the surface to penetrate into the pores formed by water evaporation.

The mathematical model solved in the present work allowed to estimate the thickness of the dehydrated zone $\left(d_{Z}=L-x_{1}\right)$.

Figure 2.9 shows OU versus frying time for both coated and uncoated samples. Simultaneously, the same figure shows the growth of the dehydrated zone with frying time. The predicted dehydrated zone thickness curve as a function of time is the same for coated and uncoated samples, according to the proposed mathematical model. A simple equation was proposed to interpret experimental results:

$$
O U=a\left(1-e^{-b t}\right)
$$

where

$a$ is the oil concentration at long times

$b$ is the coefficient that takes into account the structural changes as a function of frying time

The parameters of Equation 2.28 were estimated by a nonlinear regression showing high values of the correlation coefficient $r^{2}$ (Table 2.3).

Results of Figure 2.9 allowed to correlate OU with the thickness of the dehydrated zone $\left(d_{Z}\right)$ as shown in Figure 2.9b. A linear behavior of OU versus dehydrated zone thickness was maintained up to OU values of $0.031 \mathrm{~g} / \mathrm{g}$ dry solid and $0.071 \mathrm{~g} / \mathrm{g}$ dry solid for both coated and uncoated samples, respectively.

Values of OU for coated samples were lower than those of uncoated ones. For low $d_{Z}$ values, the oil retained by the surface could be incorporated into the dehydrated zone, when the sample was removed from the frying medium (linear relationship Figure 2.9b). When the dehydrated zone was large, a deviation from the linear behavior was observed. This could be attributed to the fact that the amount of oil retained at the sample surface is limited, being the oil surface wetting the property related to the interfacial tension, governing these phenomena (Mellema, 2003).

The presence of MC coating with thermal gelation properties modified the surface wetting and also became a mechanical barrier leading to a decrease in the OU of the coated samples. 

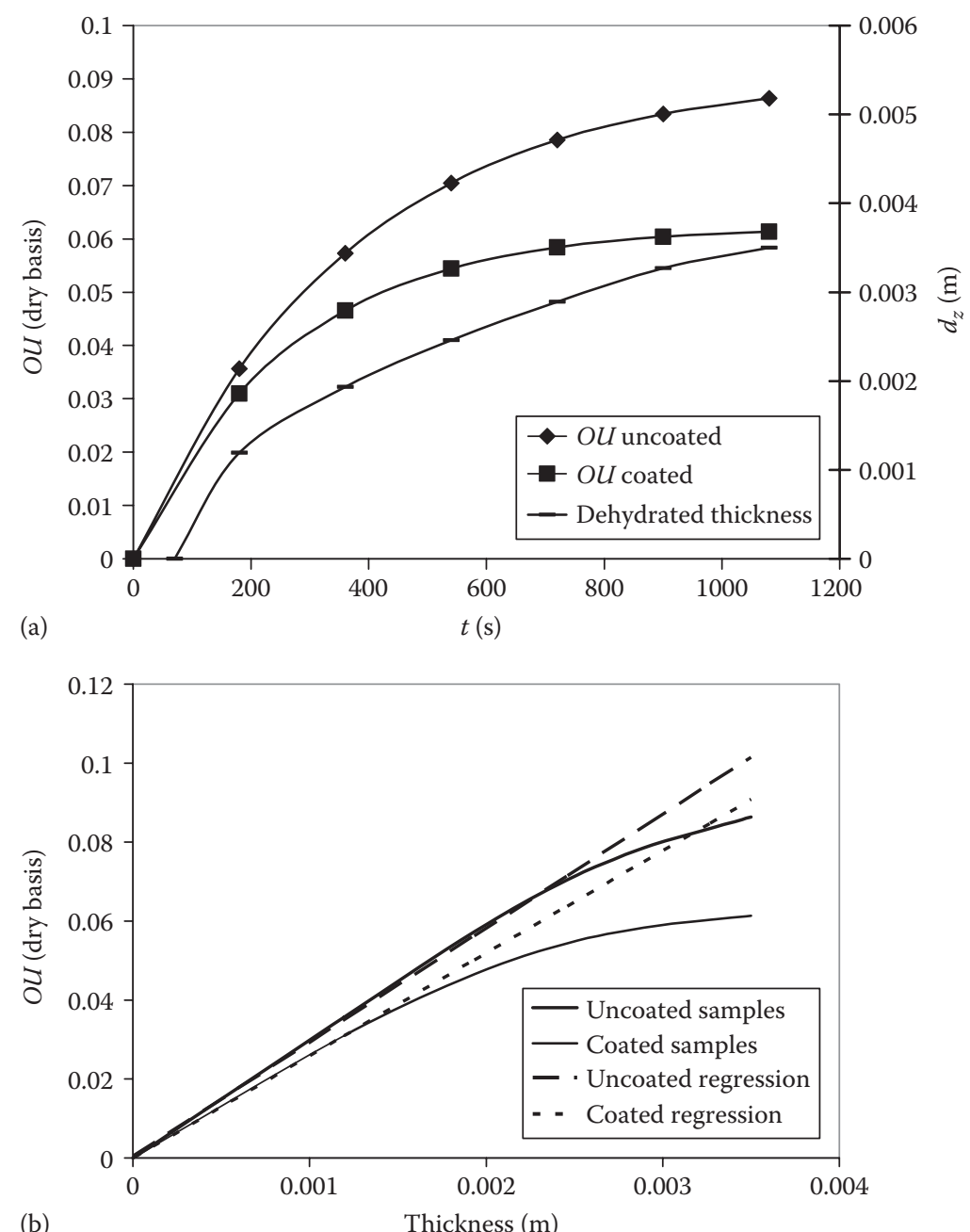

FIGURE 2.9 (a) Oil uptake of uncoated and coated samples and dehydrated zone thickness $\left(d_{T}\right)$ as a function of frying time. $d_{T}$ curve is the same for coated and uncoated samples. (b) Oil uptake of uncoated and coated samples as a function of dehydrated zone thickness.

\section{TABLE 2.3}

Gaseous Permeability $\left(\mathrm{O}_{2}\right.$ and $\left.\mathrm{CO}_{2}\right)$ of Films Based on Native Corn Starch $(\mathrm{N})$, Acetylated Starch (A), and a Mixture of Both in Equal Proportions (50N+50A), with 1.5\% p/p Glycerol $(1.5 \mathrm{G})$ and $0.3 \% \mathrm{p} / \mathrm{p}$ Potassium Sorbate $(0.3 \mathrm{KS})$

\begin{tabular}{|c|c|c|c|}
\hline Film Composition & $\begin{array}{c}\mathrm{O}_{2} \text { Permeability } \times 10^{10} \\
\left(\mathrm{~cm}^{3} / \mathrm{m} \mathrm{s} \mathrm{Pa}\right)^{2}\end{array}$ & $\begin{array}{c}\mathrm{CO}_{2} \text { Permeability } \times 10^{9} \\
\left(\mathrm{~cm}^{3} / \mathrm{m} \mathrm{s} \mathrm{Pa}\right)\end{array}$ & $\begin{array}{c}\text { Selectivity Coefficient }(\boldsymbol{\beta}) \\
\mathrm{P}_{\mathrm{CO}_{2}} / \mathrm{P}_{\mathrm{O}_{2}}\end{array}$ \\
\hline $\mathrm{N}-1.5 \mathrm{G}$ & $3.97 \pm 0.05$ & $5.37 \pm 0.27$ & 13.51 \\
\hline $\mathrm{N}-1.5 \mathrm{G}-0.3 \mathrm{KS}$ & $6.36 \pm 0.12$ & $8.30 \pm 0.88$ & 13.10 \\
\hline $50 \mathrm{~N}+50 \mathrm{~A}-1.5 \mathrm{G}$ & $3.40 \pm 0.04$ & $4.72 \pm 0.27$ & 13.87 \\
\hline $50 \mathrm{~N}+50 \mathrm{~A}-1.5 \mathrm{G}-0.3 \mathrm{KS}$ & $5.86 \pm 0.17$ & $7.81 \pm 0.56$ & 13.33 \\
\hline $\mathrm{A}-1.5 \mathrm{G}$ & $3.12 \pm 0.05$ & $4.03 \pm 0.02$ & 12.92 \\
\hline A-1.5G-0.3KS & $5.50 \pm 0.10$ & $7.62 \pm 0.12$ & 13.85 \\
\hline
\end{tabular}


The OU was also correlated with the WC showing a negative slope. At high WC, the results were linearly correlated; however, deviations were observed at $W C=0.3$ and 0.35 (dry basis) for uncoated and coated samples, respectively. Besides considering that $\mathrm{WC}$ is a function of $\mathrm{d}_{\mathrm{Z}}$, linear equations were obtained for the initial frying periods.

Following the OU criteria introduced by Pinthus and Saguy (1994), the ratio between OU and WC was obtained from Table 2.2, being 0.17 for uncoated and 0.14 for coated samples; these results agree with findings reported by Moyano and Pedreschi (2006).

\subsubsection{Final Considerations about the Modeling of Coated Fried Food}

A mathematical model of the frying process based on the numerical solution of the heat and mass transfer differential equations under unsteady-state conditions was proposed and solved using measured physical and thermal properties. It allowed to simulate satisfactorily the experimental data of temperature and WC during the different frying stages.

The model allowed the prediction of the position of the vaporization front and the thickness of the dehydrated zone as a function of frying time. WC correlated linearly with the vaporization front position corresponding to the thickness of the humidity core.

OU that occurs when the sample is removed from the frying medium was correlated with the thickness of the dehydrated zone; a linear behavior was held for the initial frying period. However, deviations were observed when the thickness of the dehydrated zone increased. This could be attributed to the fact that the amount of oil retained at the sample surface is determined by the surface tension property. OU was also linearly correlated with water loss at the initial frying stage. A simple equation for OU as a function of frying times was proposed, considering the microstructural changes developed during the frying process in which the dehydrated zone increases allowing the oil retained by the surface to penetrate into the pores left by water evaporation.

The presence of MC coating reduced the OU due to the thermal gelation behavior, modifying the wetting properties and also becoming a mechanical barrier to the oil.

The application of MC coatings reduced significantly $(p<0.05)$ the oil content of dough discs with regard to control ones, reaching a decrease of $30 \%$. However, the coating did not modify the WC of the samples, this was attributed to the hydrophilic characteristics of the films that led to poor water vapor barrier properties, besides thermal histories of coated and uncoated samples were similar.

Scanning electron microscopy techniques showed the integrity of the MC coating and good adhesion to the food product after its dehydration during the deep-oil-frying process.

\subsection{Case Study: Release of an Antimicrobial Agent from a Biodegradable Active Film to a Food System}

One of the important emerging functions of edible films and coatings is their use as carrier of antimicrobial and antifungal agents to increase shelf life of foods. This section discussed edible films as delivery matrices for antimicrobial preservatives.

Microbial contamination of food products causes serious diseases and consequent economic losses (Türe et al., 2012). The addition of bactericidal agents or growth inhibitors into food formulation by spraying or immersion methods has been employed to overcome food contamination. However, direct application of the antimicrobial agents has some limitations since they could be neutralized or evaporated or reduce their effective concentration on the surface due to a rapid and inadequate diffusion into the food bulk (Quattara et al., 2000; Pranoto et al., 2005). To overcome these problems, the incorporation of additives to film matrices has been proposed, improving food packages functionality (Cagri et al., 2001; Li et al., 2006). The active agent is slowly released from the film to the food surface, where it remains at high concentration (Gennadios et al., 1997; Quattara et al., 2000; Chollet et al., 2009).

The selection of an antimicrobial agent depends on its activity against a target microorganism. The growth of potential microorganisms that can spoil food products depends on its characteristics such as 
$\mathrm{pH}$, water activity, composition, as well as storage conditions. The direct incorporation of preservatives in packaging films is a convenient method by which antimicrobial activity can be achieved. Taking into consideration that antimicrobial activity mainly depends on the diffusion of the preservative, it is important to evaluate the release from the polymer matrix. The mathematical modeling provides information about the mechanisms that control the mass transfer process.

Within the natural polymers used in active packaging, starch is one of the most used materials due its abundance, availability, low cost, and biodegradability (López et al., 2008; García et al., 2009). Corn starch-based films are homogeneous and transparent (López et al., 2008, 2010, 2011). The addition of glycerol as a plasticizer improved material flexibility, avoiding cracks and decreasing the water vapor permeability. The use of acetylated corn starch into formulations led to the development of more resistant films that are less permeable to water vapor (López et al., 2008, 2010). Films based on native and acetylated corn starch showed a good heat sealing capacity making them appropriate materials to develop food packages (López et al., 2011). The scaling up of starch-based materials has been demonstrated since they could be processed by blown extrusion as well as thermocompression (López et al., 2013a).

Sorbic acid and its salts are widely used food preservatives; they are efficient and versatile inhibiting the most common microorganisms (fungi, molds, and yeasts) that can deteriorate foods (Kristo et al., 2008). Flores et al. (2007) studied the performance of tapioca starch-based films as carriers of sorbate and established that films were effective in controlling the growth of $Z$. bacilli population, acting as a preservative release agent or as a barrier for external yeast contamination. On the other hand, Türe et al. (2012) developed films based on wheat gluten containing PS demonstrating the antifungal properties of these active materials. The antifungal effectiveness of PS incorporated in guar gum and pea starch coatings was also reported (Mehyar et al., 2011). Pranoto et al. (2005) informed that chitosan films with PS presented antimicrobial activity against Staphylococcus aureus, Listeria monocytogenes, and Bacillus cereus. Sayanjali et al. (2011) applied an antimicrobial coating based on CMC with PS to control the growth of molds, inhibiting substantially Aspergillus species.

Despite many works present in the literature concerning active films with PS, it is still relevant to study the diffusion of the additive from the polymeric matrices to the product and its diffusion profile inside the food bulk. The mathematical modeling of this phenomenon could allow to determine active agent diffusion coefficients in both, the film and the product.

In the present section, the effectiveness of the addition of PS in corn plasticized starch films to prevent microbial growth on a food product is discussed. The sorbate release from the polymeric matrix to a semisolid model food system was evaluated, and a mathematical model of the diffusion process was proposed.

\subsubsection{Active Film Preparation and Characterization}

Starch aqueous suspensions $(5 \% \mathrm{w} / \mathrm{w})$ of native and acetylated corn starch (acetylation degree $=2.2 \%)$ as well as a combination in equal proportions were used to prepare active films (López et al., 2010). These suspensions were gelatinized at $90^{\circ} \mathrm{C}$ during $20 \mathrm{~min}$; then, glycerol as a plasticizer $(1.5 \% \mathrm{w} / \mathrm{w})$ and PS as an antimicrobial agent $(0.1 \%-0.5 \% \mathrm{w} / \mathrm{w})$ were added. The $\mathrm{pH}$ values of the filmogenic suspensions ranged between 5.55 and 5.98. Filmogenic suspensions with $\mathrm{pH}$ adjusted at 4.5 were also prepared in order to increase preservative effect of PS, considering that the undissociated form is the effective one.

Active starch films were obtained by the casting method; they were dried at $50^{\circ} \mathrm{C}$, removed from the plates, and stored at $20^{\circ} \mathrm{C}$ and $65 \%$ RH. PS incorporation did not modify the filmogenic capacity of the studied formulations; its concentration in the film was quantified using the AOAC (1977) official method based on absorbance measurement at $260 \mathrm{~nm}$ (López et al., 2013b). PS concentration in the active starch films decreased approximately $21 \%$ after 60 days storage at $20^{\circ} \mathrm{C}$ and $65 \% \mathrm{RH}$ due to sorbate degradative oxidation.

\subsubsection{Effect of PS on Optical and Barrier Properties of the Active Films}

Surface colorimetric measurements of films containing $0.3 \% \mathrm{w} / \mathrm{w}$ PS were recorded in terms of the Hunter parameters $\left(L^{*}, a^{*}, b^{*}\right)$ according to the CIE scale showing an increase in color differences. 


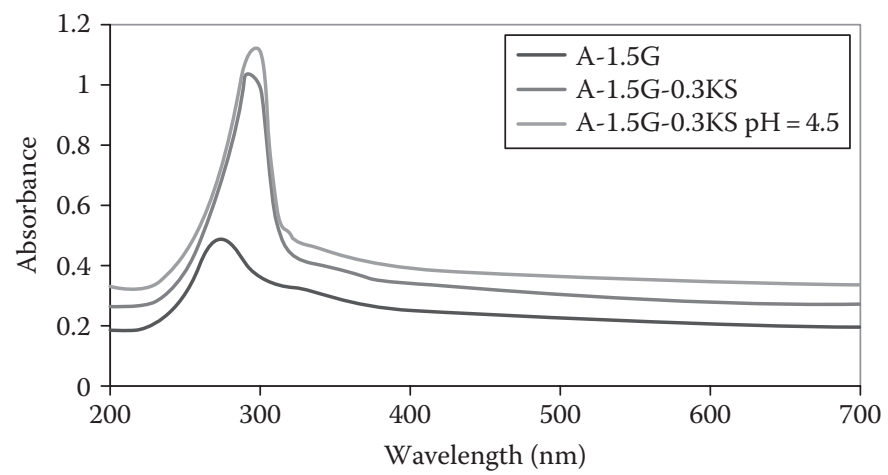

FIGURE 2.10 UV-visible spectra of acetylated corn starch films (A) containing $1.5 \% \mathrm{p} / \mathrm{p}$ glycerol (1.5G) and $0.3 \% \mathrm{p} / \mathrm{p}$ potassium sorbate $(0.3 \mathrm{KS})$ with and without $\mathrm{pH}$ adjusted to 4.5 .

This result was attributed mainly to the increase of parameter $b$, indicating that active films resulted more yellow than the control samples due to sorbate oxidative browning (Gerschenson and Campos, 1995; Famá et al., 2006). However, despite this, color modification did not affect the film acceptability.

PS addition increased the UV-barrier capacity of starch-based films, since the absorbance peak located around 270-300 $\mathrm{nm}$ increases its intensity (Figure 2.10). In general, the filmogenic suspension $\mathrm{pH}$ adjusted to 4.5 that led to an increase in the UV barrier capacity.

Water vapor barrier properties were not significantly $(p>0.05)$ affected by the addition of PS in the starch-based film. However, PS incorporation significantly increases $(p<0.05)$ film gaseous permeability, maintaining their selective permeation to $\mathrm{CO}_{2}$ and $\mathrm{O}_{2}$ (Table 2.3).

\subsubsection{Experiments to Determine PS Release from the Active Film to a Model Food System}

The effectiveness of the polymeric matrices to retain the PS was evaluated through the active agent diffusion from the starch film to a semisolid medium that simulated a food product (agar gel). This gel was prepared using an aqueous agar solution $(2 \% \mathrm{w} / \mathrm{w})$ that was molded in cylinders of $2 \mathrm{~cm}$ height and $2.5 \mathrm{~cm}$ diameter and solidified by cooling.

Film discs of $2.5 \mathrm{~cm}$ diameter containing PS were weighted and deposited onto the top surface of the agar gel cylinders and stored at $4^{\circ} \mathrm{C}$. At different times, two cylinders were taken to evaluate the sorbate release using the official method for sorbic acid (AOAC, 1977). Each cylinder was cut in four slices of $0.5 \mathrm{~cm}$ thickness, and PS concentration in each slice was determined at different times. Agar gel cylinders without film were used as controls (blanks) for the sorbate spectrophotometric determination.

\subsubsection{Mathematical Modeling of PS Diffusion Process}

PS diffusion from a medium $M_{1}$ constituted by a corn starch film containing PS to a medium $M_{2}$ (in contact with $M_{1}$ ) constituted by an agar gel, which represents a model system of an intermediated $a_{w}$ food product, was analyzed.

Fick's second law was applied; equation 29 corresponds to the unidirectional diffusion under the nonstationary state:

$$
\frac{\partial C_{i}}{\partial t}=\frac{\partial}{\partial x}\left(\frac{D_{i} \partial C_{i}}{\partial x}\right)
$$


where

$i=1,2$ corresponds to the medium $\mathrm{M}_{1}, \mathrm{M}_{2}$, respectively

$C_{i}$ and $D_{i}$ correspond to the PS concentration and the sorbate diffusion coefficient in medium $i$

$t$ is the time

$x$ is the position

A constant diffusion coefficient was considered in each medium. In the corn starch film, $x$ varied between 0 and $L_{1}$, while in the agar gel $x$ varied between $L_{1}$ and $L_{1}+L_{2}$, being $L_{2}$ the length of the gel.

The initial conditions $(t=0)$ are described by

$$
\begin{gathered}
C_{1}(x, 0)=C_{10} \text { in } 0 \leq x \leq L_{1} \\
\mathrm{C}_{2}(x, 0)=0 \text { in } L_{1} \leq x \leq L_{1}+L_{2}
\end{gathered}
$$

Boundary conditions at $t>0$ are represented by

(Continuity of the material flux)

$$
\begin{gathered}
\left.C_{2}\left(L_{1}, t\right)=K_{12} C_{1}\left(L_{1}, t\right) \text { (equilibrium at the interface } x=L_{1}\right) \\
\frac{\partial C_{2}}{\partial x}=0 \quad\left(\text { Null flux in } x=L_{1}+L_{2}\right)
\end{gathered}
$$

The software COMSOL Multiphysics Finite Element Analysis Simulation Software (USA, 2007) was used to model mathematically the experimental data.

\subsubsection{Diffusion Coefficients Determination}

Figure 2.11 shows as an example the experimental results of PS diffusion from a polymeric matrix based on native corn starch, in contact with the semisolid medium (agar gel of $a_{w} \sim 0.8$ ). When active films were tested, it was observed that $80 \%$ of the sorbate contained in the film matrix was released after $36 \mathrm{~h}$, and $91 \%$ after $60 \mathrm{~h}$. The results demonstrated that during this period active films maintained their antimicrobial action on the food product surface.

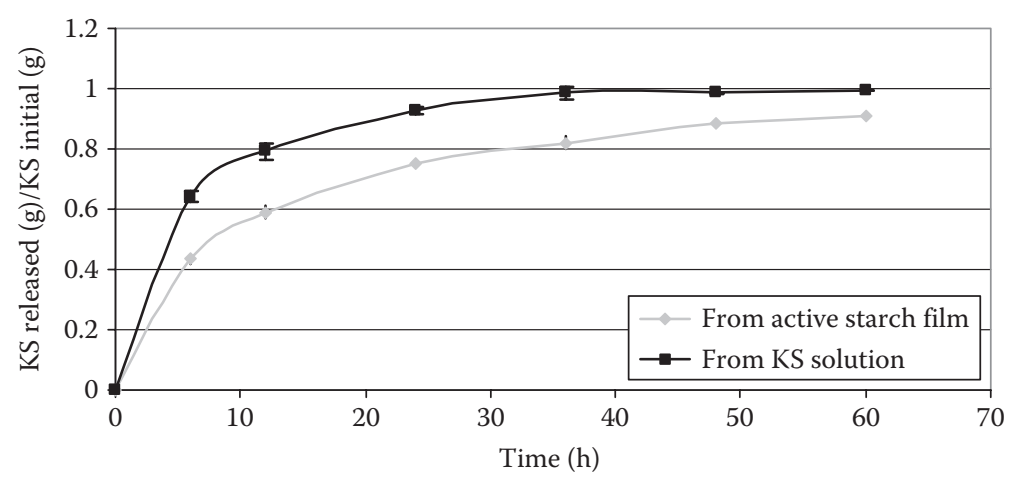

FIGURE 2.11 Potassium sorbate release from an active native starch film and from a sorbate solution to a semisolid medium as a function of time. 


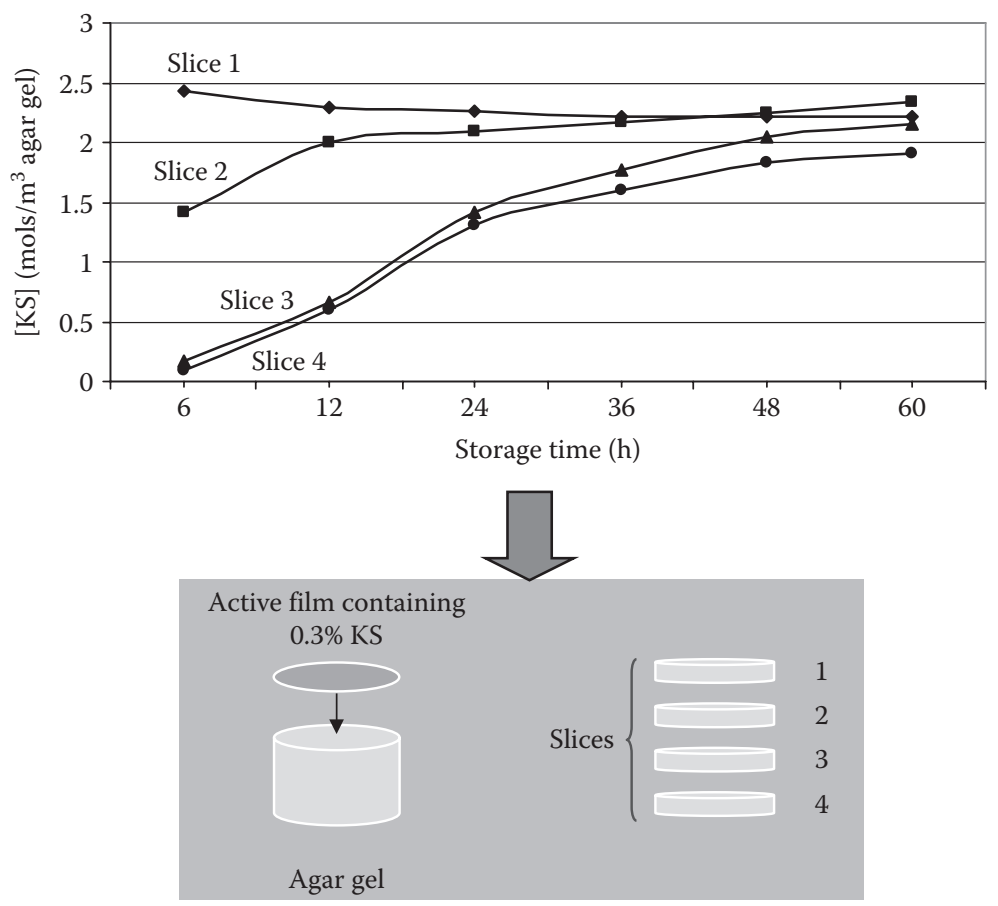

FIGURE 2.12 Potassium sorbate diffusion from the active starch films: experimental sorbate concentration profiles in the agar gel and sampling scheme.

The theoretical curves were fitted to the experimental PS concentrations to estimate diffusivity values. Calculations were performed to determine the best-fit diffusion coefficients by minimizing the sum of squares of the differences between experimental and calculated PS concentrations in the gel.

Experimental data of PS concentration in the different agar gel sections when the preservative diffused from the active starch films are shown in Figure 2.12. Experimental profiles showed that after $60 \mathrm{~h}$ PS concentration in the agar slice that was in contact with the film (slice 1) maintained a constant value.

Most of the studies found in the literature describe and model the diffusive process of different additives from films to a liquid medium, (Crank, 1975; Vojdani and Torres, 1989; Redl et al, 1996; Ozdemir and Floros, 2001; Flores et al., 2007). However, these systems do not represent a real system in which the active film is in contact with a solid food product.

AQ8 Besides, modeling the preservative diffusion process from hydrophilic matrices is of great interest not only for the food industry but also for pharmaceutical applications, since these materials are also used for controlled-release drugs (Peppas et al., 2000; Siepmann and Siepmann 2008). From the numerical simulations, the PS diffusion coefficient in the agar gel was $6 \times 10^{-10} \mathrm{~m}^{2} / \mathrm{s}$, and in the starch film matrix, it was $0.3 \times 10^{-13} \mathrm{~m}^{2} / \mathrm{s}$ (López et al., 2013).

Nonsignificant effects of starch type and controlled $\mathrm{pH}$ film formulation on PS diffusivity values were AQ9 observed. In the literature, there is a wide variation among sorbate diffusion coefficient values reported for biodegradable films. Choi and coworkers (2005) reported a value of $2.6 \times 10^{-13} \mathrm{~m}^{2} / \mathrm{s}$ for films of K-carrageenan. Redl and coworkers (1996) informed sorbate diffusion coefficients in gluten films and in bilayer systems with beeswax of $7.6 \times 10^{-12}$ and $2.7 \times 10^{-16} \mathrm{~m}^{2} / \mathrm{s}$, respectively. In whey protein films, the diffusion coefficients varied between 4.1 and $9.3 \times 10^{-11} \mathrm{~m}^{2} / \mathrm{s}$, depending on the formulation (Hasan et al., 2006).

Buonocore and coworkers (2003) developed a complex model that describes the release kinetic of different antimicrobial agents (lysozyme, nisin, and sodium benzoate) from a highly hydrophilic matrix to an aqueous medium. A more realistic model should include the swelling of the film when it is in contact with high-humidity systems. 


\subsubsection{Application of Active Films in Dairy Products: PS Minimum Inhibitory Concentration}

Each preservative that is applied in foodstuffs requires a different minimum concentration in the system to show antimicrobial effect. A dairy product was selected as a food system to determine the minimum inhibitory concentration (MIC) of PS.

A commercial cheese with high humidity content (55\%), elaborated with full cream milk acidified with lactic acid bacteria, was placed in contact with the active film.

The method proposed by Fajardo et al. (2010) was used to determine the MIC. Approximately $25 \mathrm{~g}$ of cheese were deposited onto starch films containing different PS concentrations $(0.1 \%-0.5 \% \mathrm{w} / \mathrm{w})$. Samples were stored at $20^{\circ} \mathrm{C}$ during 6 days; visual observation and photographic record were done daily. The lowest PS concentration that did not allow visual observation of fungi growth on the cheese surface was considered as MIC. Figure 2.13 shows the photographs of the cheese samples, placed on native corn starch films with glycerol $(1.5 \% \mathrm{w} / \mathrm{w})$ and containing PS at different concentrations $(0.1 \%-0.5 \% \mathrm{w} / \mathrm{w})$, stored at $20^{\circ} \mathrm{C}$ and $65 \%$ RH during 6 days.

PS MIC was $0.3 \% \mathrm{w} / \mathrm{w}$ because in these samples visible fungi growth was not detected during the storage period. The $\mathrm{pH}$ of the film formulation did not affect the obtained MIC value.

The absence of the $\mathrm{pH}$ effect could be attributed to the proximity of the sorbic acid $\mathrm{p} K_{\mathrm{a}}(4.76)$ to the assayed dairy product $\mathrm{pH}$ (4.7-5.5); thus the concentration of the nondissociated sorbate form in the interface film product would be similar in both cases.

López et al. (2013b) demonstrated that starch-based active films were able to inhibit Candida spp., Penicillium spp., S. aureus, and Salmonella spp. growth, which are microorganisms having a negative effect on quality or pathogenic bacteria responsible of some foodborne diseases.

\subsubsection{Antimicrobial Performance of the Active Film on a Dairy Product}

Starch films formulated with glycerol $(1.5 \%$ w/w) and with PS at the MIC, were formulated with and without adjusting $\mathrm{pH}$ to 4.5 .

Approximately $25 \mathrm{~g}$ of the commercial cheese described previously were deposited onto active starch films, and samples were placed into bags of thermo-sealable synthetic films (PD 141 [CRYOVAC ${ }^{\circledR}$ ] that is a polyethylene multilayer material $75 \mu \mathrm{m}$ thickness).

Fresh cheese is characterized to be a slightly fermented product with low acidity $(\mathrm{pH} \approx 5)$, high water activity, low salt content $(<3 \%)$, and with an electronegative redox potential (oxygen absence). These conditions led to the development of many microorganisms, specially molds and yeasts. Samples were stored

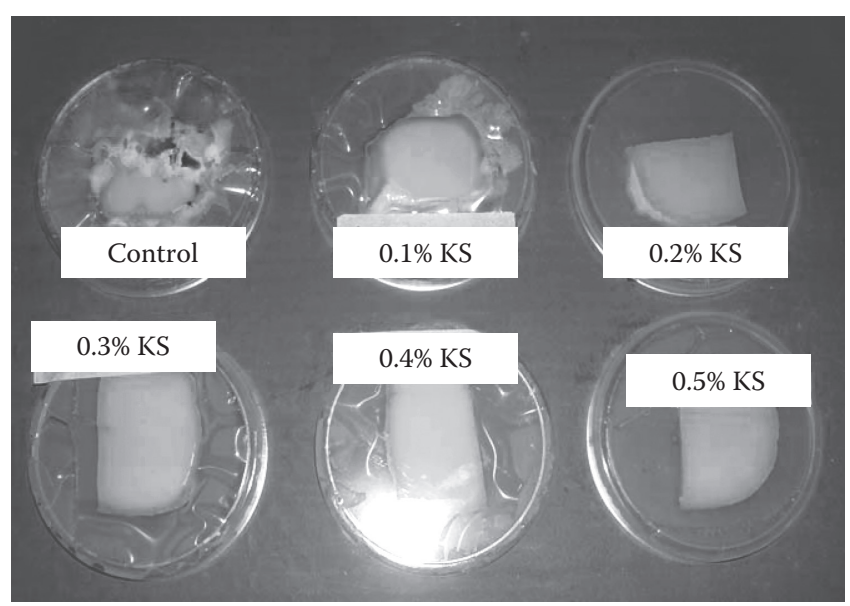

FIGURE 2.13 Cheese samples stored at $20^{\circ} \mathrm{C}$ and $65 \% \mathrm{RH}$ placed onto native corn starch film with glycerol $(1.5 \% \mathrm{w} / \mathrm{w})$ and potassium sorbate at different concentrations $(0.1 \%-0.5 \% \mathrm{w} / \mathrm{w})$. 


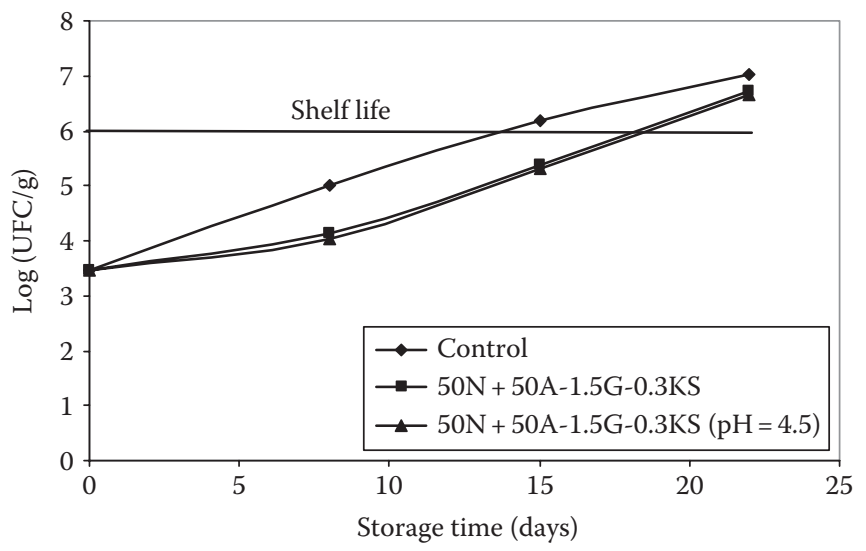

FIGURE 2.14 Yeast and molds growth on cheese samples deposited onto corn starch films based on mixtures of equal proportions of native and acetylated corn starch $(50 \mathrm{~N}+50 \mathrm{AS})$ plasticized with $1.5 \%$ glycerol $(1.5 \mathrm{G})$ containing $0.3 \%$ potassium sorbate $(0.3 \mathrm{KS})$ with $(\mathrm{pH}=4.5)$ and without $\mathrm{pH}$ adjustment. Samples were stored at $4{ }^{\circ} \mathrm{C}$.

at $4^{\circ} \mathrm{C}$; at 7, 15, and 22 days, yeasts and molds counts were determined using YGC medium (Yeast extract Glucose Chloramphenicol, Merck) incubating 8 days at $30^{\circ} \mathrm{C}$. Viable microorganisms were determined by counting the number of formed colonies, expressing the results in CFU/g cheese.

Figure 2.14 shows the microbial counts in cheese samples placed onto active films containing $0.3 \%$ PS. Shelf life of fresh cheese was defined as the time necessary to reach $10^{6} \mathrm{CFU} / \mathrm{g}$ in the sample. Several authors have stressed that when microbial counts exceed $10^{6} \mathrm{CFU} \mathrm{g}^{-1}$ toxic substances may be produced (Howard and Dewi, 1995; García et al., 2001). In the case of the control sample (packaged without the active film), the observed shelf life was 14 days; while for cheese samples stored on active films, it was extended to 17 days (Figure 2.14).

Cerqueira and coworkers (2010) stressed that galactomannan coatings were effective to prolong shelf life of regional cheese. Several authors have used chitosan-based films to extend the shelf life of different types of cheese under refrigeration or modified atmosphere storage (Gammariello et al., 2008; Del Nobile et al., 2009, Fajardo et al., 2010). On the other hand, other biodegradable materials can be used for this purpose, for example, PLA was used to package Dambo cheese maintaining its quality attributes during 84 days (Holm et al., 2006).

\subsubsection{Final Considerations about the Modeling of the Preservative Release in Active Films}

The release of PS from active films was studied using native or acetylated corn starch films. The addition of PS to the starch films increased their UV barrier capacity without modifying the water vapor permeability values. Active films resulted more yellowness and less transparent than films without PS, but these characteristics did not affect their acceptability. The PS MIC in active starch films resulted $0.3 \% \mathrm{w} / \mathrm{w}$, regardless of the corn starch type and the formulation $\mathrm{pH}$. The tested active films were effective to extend the shelf life of refrigerated cheese samples, from 14 to 17 days. The active agent release from films based on corn starch to a semisolid medium was mathematically modeled, and diffusion coefficients were determined. The PS inclusion in the starch polymeric matrices maintained a high antimicrobial concentration in the product surface, where its action is required. The developed mathematical model assumed a constant initial mass of antimicrobial that diffuses along both media that are in contact; its resolution allows to simulate diffusion processes of different additives incorporated to polymeric matrixes, taking into account only the preservative concentration and the dimensions of the film and the semisolid medium. Finally, further research should consider evaluating the eventual swelling of the film on the controlled release of active compounds. 


\section{REFERENCES}

Aguilera, J.M. (1997). Fritura de alimentos. In J.M. Aguilera (ed.), Temas de tecnología de alimentos. México, D.F.: Programa Iberoamericano CYTED, Instituto Politécnico Nacional, Vol. 1, pp. 185-214.

Aguilera, J.M. and Hernández, H.G. (2000). Oil absorption during frying of frozen parfried potatoes. Journal of Food Science, 65(3), 476-479.

Aguilera, J.M. and Stanley, D.W. (1999). Microstructural Principles of Food Processing and Engineering. Gaithersburg, MD: Aspen Publishers, Inc.

AOAC. Official Method 974.08. Sorbic acid in wines spectrophotometric method. Final action (1977). Catalá, R. and Gavara, R. (2001). Nuevos envases: De la protección pasiva a la defensa activa de los alimentos envasados. Arbor CLXVIII, 661, 109-127.

Ateba, P. and Mittal, G.S. (1994). Modelling the deep-fat frying of beef meatballs. International Journal of Food Science \& Technology, 29, 429-440, 1994.

Balasubramaniam, V.M., Mallikarjunan, P., and Chinnan, M.S. (1995). Heat and mass transfer during deep-fat frying of chicken nuggets coated with edible film: Influence of initial fat content. CoFE 1995, pp. 103-106.

Bertolini-Suárez, R., Campañone, L.A., García, M.A., and Zaritzky, N.E. (2008). Comparison of the deep frying process in coated and uncoated dough systems. Journal of Food Engineering, 84, 383-393.

Bouchon, P., Aguilera, J.M., and Pyle, D.L. (2003). Structure oil-absorption relationships during deep-fat frying. Journal of Food Science, 68(9), 2711-2716.

Bouchon, P. and Pyle, D.L. (2005a). Modelling oil absorption during post-frying cooling, I: Model development. Trans IChemE, Part C, Food and Bioproduct Processing, 83(C4), 1-9.

Bouchon, P. and Pyle, D.L. (2005b). Modelling oil absorption during post-frying cooling, II: Solution of the mathematical model, model testing and simulations. Trans IChem, Part C, Food and Bioproduct Processing, 83(C4), 1-12.

Buonocore, G.G., Del Nobile, M.A., Panizza, A., Bove, S., Battaglia G., and Nicolais, L. (2003). Modeling the lysozyme release kinetics from antimicrobial films intended for food packaging applications. Journal of Food Science, 68(4), 1365-1370.

Cagri, A., Ustunol, Z., and Ryser, E.T. (2001). Antimicrobial edible films and coatings. Journal of Food Science, 66(6), 865-870.

Campañone, L.A., García, M.A., and Zaritzky, N.E. (2010). Modelling of heat and mass transfer during deep frying process. In M. Farid (ed.), Mathematical Analysis of Food Processing. Boca Raton, FL: CRC Press, Chapter 12, pp. 331-356.

Cerqueira, M.A., Sousa-Gallagher, M.J., Macedo, I., Rodriguez-Aguilera, R., Souza, B.W.S., Teixeira, J.A., and Vicente, A.A. (2010). Use of galactomannan edible coating application and storage temperature for prolonging shelf-life of "Regional" cheese. Journal of Food Engineering, 97(1), 87-94.

Choi, J.H., Choi, W.Y., Cha, D.S., Chinnan, M.J., Park, H.J., Lee, D.S., and Park, J.M. (2005). Diffusivity of potassium sorbate in K-carrageenan based antimicrobial film. Food Science and Technology, 38(4), 417-423.

Chollet, E., Swesi, Y., Degraeve, P., and Sebti, I. (2009). Monitoring nisin desorption from a multi-layer polyethylene-based film coated with nisin loaded HPMC film and diffusion in agarose gel by an immunoassay (ELISA) method and a numerical modeling. Innovative Food Science and Emerging Technologies, 10, 208-214.

Costa, R.M., Oliveira, F.A.R., Delaney, O., and Gekas, V. (1998). Analysis of heat transfer coefficient during potato frying. Journal of Food Engineering, 39, 293-299.

Crank, J. (1975). The Mathematics of Diffusion, 2nd ed. Oxford, U.K.: Oxford University Press.

Dagerskog, M. and Sorenfor, P. (1978). A comparison between four different methods of frying meat patties: Heat transfer, yield, and crust formation. LWT: Food Science and Technology, 11, 306-311.

Debeaufort, F. and Voilley, A. (1997). Methylcellulose-based edible films and coatings: 2. Mechanical and thermal properties as a function of plasticizer content. Journal of Agricultural and Food Chemistry, 45, 685-689.

Del Nobile, M.T., Gammariello, D., Conte, A., and Attanasio, M. (2009). A combination of chitosan, coating and modified atmosphere packaging for prolonging Fior di latte cheese shelf life. Carbohydrate Polymers 78(1), 151-156.

Donhowe, I.G. and Fennema, O.R. (1993). The effects of plasticizers on crystallinity, permeability, and mechanical properties of methylcellulose films. Journal of Food Processing and Preservation, 17, 247-257. 
Fajardo, P., Martins, J.T., Fuciños, C., Pastrana, L., Teixeira, J.A., and Vicente, A.A. (2010). Evaluation of a chitosan-based edible film as carrier of natamycin to improve the storability of Saloio cheese. Journal of Food Engineering, 101, 349-356.

Famá, L., Flores, S., Gerschenson, L., and Goyanes, S. (2006). Physical characterization of cassava starch biofilms with special reference to dynamic mechanical properties at low temperatures. Carbohydrate Polymers, 66, 8-15.

Farkas, B.E., Singh, R.P., and Rumsey, T.R. (1996a). Modeling heat and mass transfer in immersion frying. I. Model development. Journal of Food Engineering, 29, 211-226.

Farkas, B.E., Singh, R.P., and Rumsey, T.R. (1996b). Modeling heat and mass transfer in immersion frying. II. Model solution and verification. Journal of Food Engineering, 29, 227-248.

Flores, S.K., Famá, L., Rojas, A.M., Goyanes, S., and Gerschenson, L. (2007). Physical properties of tapiocastarch edible Films: Influence of filmmaking and potassium sorbate. Food Research International, 40, 257-265.

Gallagher, K.M. and Corrigan, O.I. (2000). Mechanistic aspects of the release of levamisole hydrochloride from biodegradable polymers. Journal of Controlled Release, 69, 261-272.

Gammariello, D., Chillo, S., Mastromatteo, M., Di Giulio, S., Attanasio, M., and Del Nobile, M.A. (2008). Effect of chitosan on the rheological and sensorial characteristics of apulia spreadable cheese. Journal of Dairy Science, 91(11), 4155-4163.

García, M.A., Ferrero, C., Bértola, N., Martino, M., and Zaritzky, N. (2002). Edible coatings from cellulose derivatives to reduce oil uptake in fried products. Innovative Food Science and Emerging Technologies, 3, 391-397.

García, M.A., Ferrero, C., Bértola, N., Martino, M., and Zaritzky, N. (2004). Methylcellulose coatings reduce oil uptake in fried products. Food Science and Technology International, 10(5), 339-346.

García, M.A., Martino, M., and Zaritzky, N. (2001). Composite starch-based coatings applied to strawberries (Fragaria $\times$ ananassa). Nahrung/Food, 45(4), 267-272.

García, M.A., Pinotti, A., Martino, M., and Zaritzky, N. (2009). Composite edible films and coatings. In M. Embuscado and K. Huber (eds.), Edible Films and Coatings for Food Applications. Pondicherry, India: Springer Science, Chapter 6, pp. 169-210.

Gennadios, A., llanna, M.A., and Kurth, L.B. (1997). Application of edible coatings on meats, poultry and seafoods: A review. Lebensmittel-Wissenschaft \& Technologie, 30, 337-350.

Gerschenson, L.N. and Campos, C.A. (1995). Sorbic acid stability during processing and storage of high moisture foods. In G. Barbosa Canovas and J. Welti Chanes (eds.), Food Preservation by Moisture Control. Lancaster, PA: Technomic Publishing, pp. 761-790.

Hasan, S., Deniz, S., and Murat, O. (2006). A mathematical model for potassium sorbate diffusion through whey protein films. Drying Technology: An International Journal, 24(1), 21-29.

Holm, V.K., Mortensen, G., Vishart, M., and Agerlin Petersen, M. (2006). Impact of poly-lactic acid packaging material on semi-hard cheese. International Dairy Journal, 16, 931-939.

Howard, L.R. and Dewi, T. (1995). Sensory, microbiological and chemical quality of mini-peeled carrots as affected by edible coating treatment. Journal of Food Science, 60(1), 142-144.

Huse, H.L., Mallikarjunan, P., Chinnan, M.S., Hung, Y.C., and Phillips, R.D. (1998). Edible coatings for reducing oil uptake in production of akara (deep-fat frying of cowpea paste). Journal of Food Processing and Preservation, 22, 155-165.

Kassama, L.S. (2003). Pore development in food during deep-fat frying. Department of Bioresource Engineering, Macdonald Campus of McGill University, Sainte-Anne-de-Bellevue, Quebec, Canada.

Kristo, E., Koutsoumanis, K.P., and Biliaderis, C.G. (2008). Thermal, mechanical and water vapor barrier properties of sodium caseinate films containing antimicrobials and their inhibitory action on Listeria monocytogenes. Food Hydrocolloids, 22, 373-386.

Krochta, J.M. and De Mulder-Johnston, C. (1997). Edible and biodegradable polymers films: Challenges and opportunities. Food Technology, 51(2), 61-74.

Lacroix, M. (2009). Mechanical and permeability properties of edible films and coatings for food and pharmaceutical applications. In M.E. Embuscado and K.C. Huber (eds.), Edible Films and Coatings for Food Applications. New York: Springer.

Li, Y.H., Liu, B., Zhao, Z.B., and Bai, F.W. (2006). Optimized culture medium and fermentation conditions for lipid production by Rhodosporidium toruloides. Chinese Journal of Biotechnology, 22(4), $650-656$. 
López, O., García, M., and Zaritzky, N. (2008). Film forming capacity of chemically modified corn starches. Carbohydrate Polymers, 73, 573-581.

López, O.V., Giannuzzi, L., Zaritzky, N.E., and García, M.A. (2013b). Potassium sorbate controlled release from corn starch films. Materials Science and Engineering C, 33, 1583-1591.

López, O.V., Lecot, C.J., Zaritzky, N.E., and García, M.A. (2011). Biodegradable packages development from starch based heat sealable films. Journal of Food Engineering, 105(2), 254-263.

López, O.V., Zaritzky, N.E., and García, M.A. (2010). Novel sources of edible films and coatings. Stewart Postharvest Review, 6(3), 1-8.

López, O.V., Zaritzky, N.E., Grossmann, M.V.E., and García, M.A. (2013a). Acetylated and native corn starch blend films produced by blown extrusion. Journal of Food Engineering 116, 286-297.

Mallikarjunan, P., Chinnan, M.S., Balasubramaniam, V.M., and Phillips, R.D. (1997). Edible coatings for deep-fat frying of starchy products. LWT: Food Science and Technology, 30, 709-714.

Mehyar, G.F., Al-Ismail, K., Han, J.H., and Chee, G.W. (2011). Characterization of edible coatings consisting of pea starch, whey protein isolate, and carnauba wax and their effects on oil rancidity and sensory properties of walnuts and pine nuts. Journal of Food Science, 77(2), 52-59.

Mellema, M. (2003). Mechanism and reduction of fat uptake in deep-fat fried foods. Trends in Food Science and Technology, 14, 364-373.

Moreira, R.G. and Barrufet, M.A. (1998). A new approach to describe oil absorption in fried foods: A simulation study. Journal of Food Engineering, 31, 485-498.

Moreira, R.G., Palau, J., Sweat, V.E., and Sun, X. (1995). Thermal and physical properties of tortilla chips as a function of frying time. Journal of Food Processing and Preservation, 19, 175-189.

Moyano, P.C. and Pedreschi, F. (2006). Kinetics of oil uptake during frying of potato slices: Effect of pretreatments. LWT: Food Science and Technology, 39(3), 285-291.

Ni, H. and Datta, A.K. (1999). Moisture, oil and energy transport during deep-fat frying of food materials. Trans IChemE, Part C, Food Bioproduct Processing, 77, 194-204.

Ozdemir, M. and Floros, J.D. (2001). Analysis and modeling of potassium sorbate diffusion through edible whey coating films. Journal of Food Engineering, 47(2), 149-155.

Peppas, N.A., Bures, P., Leobandung, W., and Ichikawa, H. (2000). Hydrogels in pharmaceutical formulations. European Journal of Pharmaceutics and Biopharmaceutics, 50, 27-46.

Perkins, E.G. and Erikson, M.D. (1996). Deep Frying: Chemistry, Nutrition, and Practical Applications. Champaign, IL: AOCS Press.

Pinthus, E.J. and Saguy, I.S. (1994). Initial interfacial tension and oil uptake by deep-fat fried foods. Journal of Food Science, 59(4), 804-807.

Pranoto, Y., Rakshit, S.K., and Salokhe, V.M. (2005). Enhancing antimicrobial activity of chitosan films by incorporating garlic oil, potassium sorbate and nisin. LWT: Food Science and Technology, 38, 859-865.

Quattara, B., Simard, R.E., Piette, G., Begin, A., and Holley, R.A. (2000). Diffusion of acetic and propionic acids from chitosan-based antimicrobial packaging films. Journal of Food Science, 65, 768-773.

Quintavalla, S. and Vicini, L. (2002). Antimicrobial food packaging in meat industry. Meat Science, 62(3), 373-380.

Rayner, M., Ciolfi, V., Maves, B., Stedman, P., and Mittal, G.S. (2000). Development and application of soyprotein films to reduce fat intake in deep-fried foods. Journal of the Science of Food and Agriculture, 80, 777-782.

Redl, A., Gontard, N., and Guilbert, S. (1996). Determination of sorbic acid diffusivity in edible wheat gluten and lipid film. Journal of Food Science, 61, 116-120.

Rice, P. and Gamble, M.H. (1989). Modeling moisture loss during potato slice frying. International Journal of Food Science \& Technology, 24, 183.

Sayanjali, S., Ghanbarzadeh, B., and Ghiassifar, S. (2011). Evaluation of antimicrobial and physical properties of edible film based on carboxymethyl cellulose containing potassium sorbate on some mycotoxigenic Aspergillus species in fresh pistachios. LWT: Food Science and Technology, 44(4), 1133-1138.

Siepmann, J. and Siepmann, F. (2008). Mathematical modeling of drug delivery. International Journal of Pharmaceutics, 364, 328-343.

Singh, R.P. (1995). Heat and mass transfer in foods during frying. Food Technology, 49(4), 134-137.

Singh, R.P. (2000). Moving boundaries in food engineering. Food Technology, 54(2), 44-53.

Tharanathan, R. (2003). Biodegradable films and composite coatings: Past, present and future. Critical Review in Food Science and Technology, 14, 71-78. 
Türe, H., Gällstedt, M., and Hedenqvist, M.S. (2012). Antimicrobial compression-moulded wheat gluten films containing potassium sorbate. Food Research International, 45, 109-115.

Ufheil, G. and Escher, F. (1996). Dynamics of oil uptake during deep-fat frying of potato slices. LWT: Food Science and Technology, 29(7), 640-644.

Vojdani, F. and Torres, J.A. (1989). Potassium sorbate permeability of methylcellulose and hydroxypropyl methylcellulose coatings: Effect of fatty acids. Journal of Food Processing and Preservation, 13, 417-430.

Williams, R. and Mittal, G.S. (1999a) Water and fat transfer properties of polysaccharide films on fried pastry mix. LWT: Food Science and Technology, 32, 440-445.

Williams, R. and Mittal, G.S. (1999b). Low-fat fried foods with edible coatings: Modeling and simulation. Journal of Food Science, 64(2), 317-322.

Yamsaengsung, R. and Moreira, R.G. (2002a). Modeling the transport phenomena and structural changes during deep-fat frying: Part I Model development. Journal of Food Engineering, 53, 1-10.

Yamsaengsung, R. and Moreira, R.G. (2002b). Modeling the transport phenomena and structural changes during deep-fat frying: Part II Model solution and validation. Journal of Food Engineering, 53, 11-25.

\section{AUTHOR QUERIES}

[AQ1] Please check if edit to sentence starting "These films could..." is correct.

[AQ2] Please provide details of Farid (2002) and Farid and Chen (1998) in the reference list.

[AQ3] Please specify "a" or "b" for Yamsaengsung and Moreira (2002), Williams and Mittal (1999), and López et al. (2013).

[AQ4] Please check if the heading "Mathematical Model of Heat and Mass transfer during Frying Process" is correct as edited.

[AQ5] Please provide caption for parts (a) and (b) in Figure 2.2.

[AQ6] Please check if edit to the sentence starting "The use of..." is correct.

[AQ7] Please check the term " $Z$. bacilli population" for clarity.

[AQ8] Please check if edit to sentence starting "Besides, modeling the..." is correct.

[AQ9] Please check if edit to sentence starting "In the literature..." is correct.

[AQ10] Please provide proceeding location for Balasubramaniam et al. (1995). 